\title{
The Y-Chromosome STRs Profile of Louis XVII (1785-1795?)
}

\section{Gérard Lucotte $^{1}$, Christian Crépin ${ }^{2}$, Thierry Thomasset ${ }^{3}$}

\author{
${ }^{1}$ Institut d'Anthropologie Moléculaire, 75005 Paris, France \\ ${ }^{2} 15 \mathrm{~B}^{\mathrm{d}}$ de la Pierre Blanche, 11000 Carcassone, France \\ ${ }^{3}$ Service d'Analyse Physico-Chimique, UTC, 50201, Compiègne, France
}

\begin{abstract}
We have studied by SEM-EDX some hairs from a lock of hair of the King of France Louis XVI and Queen Marie-Antoinette 's children. Among these hairs, the blond hair number three is covered with skin-cells and dandruffs. The mtDNA haplogroup of dandruffs of this hair is that of Marie-Antoinette ; the Y-STRs profile of this hair is that of Louis XVI, previously known. Consequently this hair is one of Louis XVII, one of Louis XVI's son.
\end{abstract}

Keywords: Y-Chromosome STRs Profile, Louis XVII, King Louis XVI ‘s Paternity

Louis-Charles (born in 1785) is the second son of the King of France Louis XVI (1754-1793) and of Queen Marie-Antoinette (1755-1793). Louis-Charles was proclaimed Louis XVII, King of France, immediately after his father's death. Previously (Lucotte et al. , 2015) we have compared mitochondrial DNA (mtDNA) sequence, obtained from Louis XVII 's authentic hairs, with that of Marie-Antoinette ; but, until now, we were not able to obtain Louis XVII 's Y-STRs (Short Tandem Repeats DNA markers of the Y-chromosome) profile. In the present study we find - on another hair material - Louis XVII 's Y-STRs profile and we compare it to that of Louis XVI, which we recently published (Lucotte et al. , 2016).

\section{Materials and Methods \\ Materials}

On June 26 2011, the de Baudreuil brothers displayed two objects coming from their inheritance at the Rouillac office (Cheverny, France) (Figure 1) : i : a gold ring of Queen Marie-Antoinette, surrounded by her hairs ; ii : a folded letter, with inscriptions. The ring was kept in a case, where we can see the following inscription : "Cheveux de la Reine Marie Antoinette"" (Hairs of Queen Marie Antoinette), "Bague donnée par la Reine en 1792 à la $\mathrm{M}^{\text {ise }}$ de Soucy née de Makau Sous-Gouvernante des Enfants de France" (Ring given by the Queen in 1792 to the Marquise de Soucy born de Makau sub-governess of the Children of France). Renée-Suzanne-Marie Louise of Mackau (1758-1841) was sub-governess of the children of France in 1780.

Laure-Adélaïde-Louise de Fitte de Soucy married in 1863 Emile-Alexandre-Louis de Baudreuil, and the de Baudreuil brothers are, today, the descendants of this couple. Laure-Adélaïde-Louise de Fitte de Soucy was a daughter of Philippe-Babolin de Fitte de Soucy (1807-1843), himself a son of Louis-Xavier de Fitte (1775-1840) Marquis de Soucy. Louis-Xavier de Fitte was the elder son of François-Louis de Fitte (1751-1793) and Renée-Suzanne-Marie-Louise de Mackau.

At the surface of the folded letter (Figure 2) we can see the following inscription: "Cheveu des Augustes enfants de France" (Hairs from the Auguste children of France). In the unfolded paper of the letter is a lock of hair, tied up with a green thread.

\section{Microscopy techniques.}

The hairs and other objects were examined in confocal stereoscopic micrography.

Electronic microscopy was realized by Scanning Electron Microscopy (SEM) with the Philips XL30 model (environmental version). GSE and BSE procedures were used, the last one to detect heavy elements. The blond hair number 3 was examined with another electron microscope (SEM-2), the FEI model Quanta 250f FEG apparatus ; that was the LFD procedure that was used.

Elemental analyses for each object were realized on SEM-1 by X-Ray Microfluorescence (XRMF), this microscope being equipped with a Bruker AXS Energy Dispersive X-ray (EDX) ; the system of analysis is PGT (Spirit Model, of Princeton Gamma Technology). Each elemental analysis is given in the form of a spectrum, with kiloelectrons / Volts (ke/V) on the abscissa and elemental peak heights in ordinates. 


\section{DNA Techniques}

Genomic DNA was extracted (Lucotte, 2010) from the blond hair number 3 using a standard method (0.5M EDTA, sarcosyl $20 \%$ and proteinase K $10 \mathrm{mg} / \mathrm{ml}$ ) and purified using a commercial kit (NucleoSpin $^{+}$Kit ; Macherey-Nagel, Duren, Germany) in accordance with the manufacturer's instructions.

From this extracted genomic DNA, we obtain the mtDNA sequence intervals for HVR1 and HVR2 (Hypervariable Regions 1 and 2) by PCR (Polymerase Chain Reaction) with primers F15971 and R16410 and with primers L15 and H484, respectively. PCR products were purified from agarose gel. Both strands of the amplified mt-DNA fragments removed were directly sequenced (Big Dye Terminator Cycle sequencing kit ; Applied Biosystems).

From the extracted genomic DNA, we amplified 16 Y-STRs by using the AmpFirst Identifier PCR amplification kit (Amp FIRSTY filer ${ }^{\mathrm{TM}}$, Applied Biosystems), according to the instructions given by the Company ; this amplification kit is specially adapted to the study of ancient DNA.

\section{RESULTS}

\section{The paper of the letter.}

The paper corner located in the upper right part of the unfolded

letter was cut of for analysis. Examined in optical microscopy (Figure 3), it is of green colour. Some part of it, examined by SEM (in GSE), at magnification of $x 100$, shows that it is made up of an untertwine of intact vegetal fibers.

The global spectrum of this part shows elevated peaks (of carbon and oxygen) corresponding to an organic matter. Figure 4 shows the SEM photograph of some portion of such a fiber ; it corresponds to a textile fiber of linen (a cylindric fiber, of about $20 \mu \mathrm{m}$ of thickness, of which the smooth surface shows regularly spaced characteristic nodes). Elemental analysis of this fiber shows a spectrum similar to that of the global spectrum of the paper.

This paper is a "papier-chiffon", a sort of luxurious paper that was used in the past for the writing of the official and fiduciary documents. Presence of sulphur, potassium and aluminium in spectras suggest that alun (a sulphate double of potassium hydrated), of chemical formula : $\mathrm{KAl}\left(\mathrm{SO}_{4}\right)_{2}, 12 \mathrm{H}_{2} 0$ was used as a mordant to stain the paper with some green organic colouring.

\section{The ink of the paper inscription.}

Figure 5 shows enlarged views (both in optical and electronic microscopy) of the upper part of the terminal letter s of the written word "des". Spectrum of the white matter (seen in BSE) located at this point (Figure 6) shows that the corresponding bright particles are sulphur and iron-rich.

This indicates that the ink is a "ferro-gallic ink", iron sulphate particles added darkening again the blackness of the organic matter constituting the ink. This sort of ferro-gallic ink was commonly used in Europe (from the Middle-Ages to the end of the $18^{\text {th }}$ Century, and even after).

\section{The green thread around the lock of hair.}

Figure 7 shows an enlarged optical view of the lock of hair. There are two sorts of hair colouring : blond hairs and red hairs. Both these sorts of hair are rolled up (and tied) with a green thread.

Figure 8 shows different aspects of the fibers constituting such a thread. Green in colour the fibers are long and cylindrical, with a regular thickness. The lower SEM photograph of the figure shows one fiber extremity, with a bi-triangular end characteristic of a silk fiber. Figure 9 shows some portion of such a fiber (of $16 \mu \mathrm{m}$ of thickness), which is smooth. The corresponding spectrum shows a main peak of carbon, a little peak of oxygen, and a very little peak of sulphur (this last organic element being characteristic of silk).

But they are also aluminium and sulphur little peaks in the spectrum. Like for the paper, the green colour of the silk fibers is due to an organic green pigment linked to the silk by the alun mordant.

\section{The hairs of the lock.}

Three hairs of each colour were taken from the lock (Figure 10). The following figures summarize results we obtained concerning the longest hair for each category.

Figure 11 shows both extremities of red hair number 1 ; they correspond to a hair that was cut off (direction of the point scales of each row permitting to orientate the hair). SEM-1 photograph of Figure 12 shows the middle part of the hair, where the thickness is of $65.5 \mu \mathrm{m}$. On this photograph we can see that the average distance between the scale row is about $5 \mu \mathrm{m}$, a characteristic of human hair ( the hair surface is covered with mineral particles). The spectrum shows the peaks characteristics of hair composition : two peaks (of organic matter) corresponding to carbon and oxygen, a very little peak of nitrogen, and a consistent peak of sulphur (disulphur bridges of the keratin); there are chlorine 
and sodium, corresponding to the salt $(\mathrm{ClNa})$ of sweat. An example of a mineral deposit on the hair surface is shown on Figure 13 ; its spectrum is that of an alumina-silicate iron-rich (a clay) particle. A total number of thirty-two of such particles are deposited on the hair surface. Photograph of Figure 14 shows another example of an other sort of mineral deposit on the hair surface ; its spectrum shows a relatively elevated main peak of calcium (so it is that of calcite, or another form of calcium carbonate). We found a total number of eleven such particles on the hair surface. Figure 15 shows an example of an Acari body portion adhering to the hair surface (four of such shells -or shell fragments - were found, stuck to the scales). The hair surface is multi-parasited, because we observe on its surface a clutch of some sort of Arthropod. We have evidence that this sort of hairs were treated with iron sulphate (Figure 16), a commonly used phytosanitary product of chemical formula $\mathrm{FeSO}_{4}$. We have also observed at least four samples of Cyanophycaes (Figure 17) parasiting the hair surface.

Figure 18 shows both the cut extremities of blond hair number 1. SEM-1 photograph and spectrum of Figure 19 show that this hair is, by aspect and composition, a typical human hair. Its diameter in the middle part is of $56.2 \mu \mathrm{m}$. Exploration of its surface shows only two clay particles and one calcium carbonate particle (we do not find any iron sulphate product). Figure 20 shows an adhering skin-cell, of the same chemical composition than that of hair scales (but differing for lower relative sulphur content and by the presence of phosphorous). An example of a micel of soap is shown on the SEM photograph of Figure 21 (its composition is mainly of carbon and oxygen); we found six samples of such a product on the hair surface, this attesting that this hair was intensively washed, soaped and cleaned. Photograph of Figure 22 shows an example of a set of metallic particles (of silver sulfure, with traces of copper) that is loaded on the hair surface (four sets of such a product were found). This attests that the hair was finely silver-decorated after washing. Figure $\mathbf{2 3}$ shows the unique example found of a set of at least three particles (with angular outlines) located on the hair surface. As these structures are highly-resistant to an intense (at the maximal power of the SEM apparatus) X-ray fine beam and that their chemical compositions are mainly of carbon, they are probably diamond micro-splinters particles.

So, the two hairs are cut off hairs ; both are similar in aspect and chemical composition, that are characteristic of human hairs. Table 1 shows the main points by which they differ.

Table 1 : Main differences between the two hairs.

\begin{tabular}{|c|c|c|}
\hline 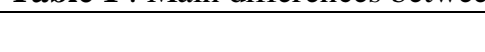 & Red hair & Blond hair \\
\hline Thickness & $65.5 \mu \mathrm{m}$ & $56.2 \mu \mathrm{m}$ \\
\hline Deposits on the scales surface & numerous & few \\
\hline Numbers of clay particles & 32 & 2 \\
\hline $\begin{array}{l}\text { Numbers of calcium carbonate } \\
\text { particles }\end{array}$ & 11 & 1 \\
\hline Number of skin-cells & none & 1 \\
\hline Numbers of Acari shields & 4 & none \\
\hline Number of insect clutch & 1 & none \\
\hline Numbers of Cyanophycaes & 4 & none \\
\hline Numbers of $\mathrm{FeSO}_{4}$ particles & 6 & none \\
\hline Numbers of soap micels & none & 6 \\
\hline $\begin{array}{l}\text { Numbers of metallic particles of } \\
\text { silver sulfure }\end{array}$ & none & 4 \\
\hline Diamond micro-splinters set & none & 3 \\
\hline
\end{tabular}

The two sorts of hairs entangled in the lock differ by their preparations : while blond hair was carefully soaped and washed and after that decorated with some precious materials, red hair is more "native" because more covered by clay and calcium carbonate earth minerals - and constitutes a dirty matter; that hair is covered by arthropod remains and infected by some Cyanophycaes (iron sulphate was used to treat it). These two sorts of hairs (unwashed red hairs and washed and decorated blond hairs) were further entangled in the hair lock we observe.
The following figures show skin-cells and dandruffs found on the blond hair number 3 surface. This hair, previously studied, has been shown especially rich with these formations ; so, a special procedure (on SEM-2, in LFD, 2400x) was used to analyse it more precisely.

Figure 24 shows the first skin-cells found ; of a relatively great size (about $30 \mu \mathrm{m}$ of maximal length), these cells are flattened and longitudinally folded. Their compositions are about the same to those of hair scales, but with phosphorus and a 
relatively lower proportion of sulphur. Figure $\mathbf{2 5}$ shows the first dandruff found ; similar in composition to that of skin-cells, it has a smaller size, a bulging surface and well delimited contours. Figure 26 shows the second dandruff observed, and Figure 27 the aspects of the two following dandruffs found. The full-length exploration of the blond hair number 3 surface allows us to detect about thirty dandruffs on it.
Contrary to skin-cells, dandruffs are multi-nucleated cells that contain appreciable amounts of nuclear and cytoplasmic DNA (Lucotte and Bouin Wilkinson, 2014). It is the reason why we have extracted genomic DNA from the whole blond hair number 3 .

\section{DNA of the blond hair number 3}

We obtained about 39ng of genomic DNA from the blond hair number 3 . The detection procedure of the mtDNA mutations was replicated twice. Table 2 summarizes results we obtain.

Table 2 : Detection of mtDNA mutations.

\begin{tabular}{|l|l|l|}
\hline & Present study & Lucotte et al., 2015 \\
\hline HVR1 sequence & no mutation & no mutation \\
\hline HVR2 sequence & $152 \mathrm{C}, 194 \mathrm{~T}$, 263G, 315.1C & $152 \mathrm{C}, 194 \mathrm{~T}, 263 \mathrm{G}, 315.1 \mathrm{C}$ \\
\hline
\end{tabular}

There is no mutation in the HVR1 sequence, and four mutations (152C, 194T, 263G and 315.1C) in the HVR2 sequence; these mutations are the same as those previously found (Lucotte et al., 2015) in the other authentic hairs of Louis XVII. This combination (sometimes improperly called "the Habsbourg haplotype") was initially found (Jehaes et al. , 2001) in some present time descendants of Marie-Antoinette (notably for the present day living Queen Anna of Romania).
We have very recently (Lucotte, in preparation) established (for Marie-Antoinette's authentic hairs, kept in a medallion) that the corresponding mtDNA haplogroup is truly the one that belongs to Queen Marie-Antoinette. Consultation of recent data-banks has shown that this mtDNA haplogroup is rare (it was found in less than twenty subjects in the world).

The detection procedure of the Y-STRs profile was also replicated twice. Table $\mathbf{3}$ summarizes results we obtain concerning this profile.

Table 3. Detection of allele values for fifteen Y-STRs.

\begin{tabular}{|l|l|l|}
\hline Y-STRs & \multicolumn{2}{c|}{ Allele values } \\
\hline DYS19 & Present study & Lucotte et al., 2016 \\
\hline DYS385.a & 14 & 14 \\
\hline DYS385.b & 11 & 11 \\
\hline DYS389.I & 14 & 14 \\
\hline DYS389.b & 14 & 14 \\
\hline DYS390 & 16 & 16 \\
\hline DYS391 & 23 & 23 \\
\hline DYS392 & 11 & 11 \\
\hline DYS393 & 13 & 13 \\
\hline DYS438 & 13 & 13 \\
\hline Y-GATA-A4 & 12 & 12 \\
\hline DYS448 & 13 & 13 \\
\hline DYS456 & 19 & 19 \\
\hline DYS458 & 16 & 16 \\
\hline Y-GATA-C4 & 18 & 18 \\
\hline Y-GATA-H4 & 23 & $?$ \\
\hline & 12 & 12 \\
\hline
\end{tabular}

Allele values are identical for fourteen Y-STRs. That confirms that Louis XVII is truly Louis XVI's son.

\section{DISCUSSION AND CONCLUSION}

We worked on a lock of hair kept in a letter which, together with a ring entangled with MarieAntoinette's hairs, were given at that time to the Marquise de Soucy (born de Makau). The letter was passed on by inheritance to the Soucy today descendants. SEM-EDX analyses of the letter paper have shown that it is a special sort of "papierchiffon", constituted mainly of linen fibers ; the ink of the inscription on the paper was a special sort of ferro-gallic ink. Both these materials are compatible with those of a letter written in the $18^{\text {th }}$ Century. 
The lock of hair kept in the letter is surrounded and tied by a precious green silk threads. There are two sorts of hairs in the lock concerning colour : red hair and blond hair. This indicates that the lock of hair is constituted by the hair of two different subjects.

The two sorts of hair differ also by the diameters : a thickness of $65.5 \mu \mathrm{m}$ for a red hair (red hair number 1 being taken as an example), and of $56.2 \mu \mathrm{m}$ for a blond hair (blond hair number 1 being taken as an example). The main diameter of a normal adult hair is about $80 \mu \mathrm{m}$ (Deedrick and Koch, 2014), and dessication (as for hairs studied here) is responsible of a limited reduction only of this thickness. A hair thickness of $65.5 \mu \mathrm{m}$ (corresponding to the normal increase of the hair diameter during growth) is suggestive of that of a teenager, and a hair thickess of $56.2 \mu \mathrm{m}$ of that of a younger subject.

The hair colour differenciation, by itself, must also be taken in consideration : we know that the hair colour of the young Louis-Charles was blond, while his elder sister Marie-Thérèse (1778-1851) had red hair, or more exactly (just like her mother, MarieAntoine) "blond-cendré".

The two sorts of hair-coloring are also important to consider. We think that these two colorations correspond to two subjects only (the inscription, in the plural, "Cheveus des Augustes enfants de France" indicates that they were only two), whose hair is in the lock : these two subjects are Louis-Charles and Marie-Thérèse. The first Dauphin Louis-Joseph (born in 1781) died in 1789, and the last child Sophie (born in 1786) died one year after. As Marie-Antoinette had given to Renée de Soucy the ring (and the hairs) in 1792, the two surviving children were alive at that time.

We established that, unlike red hairs, blond hairs were carefully prepared (washed, soaped and decorated) ; these two sorts of hairs were, secondarily, intertwined in the lock. This is an ancient usual process of hair embracing, concerning persons who are affectively or/and familiarly tightly linked ; for example (Lucotte et al. , 2016), we have observed that Louis XVI's hairs and those of his wife
Marie-Antoinette are intertwined this way in the lock of hair studied.

We have observed that blond hair number 3 is particularly charged with skin-cells and dandruffs, tightly linked to its surface. A sufficient quantity of DNA was extracted from it ; the corresponding mtDNA mutations detected correspond to a particular mtDNA haplogroup that is the same than that obtained from another Louis XVII 's authentic hair (Lucotte et al., 2015), and that of Marie-Antoinette.

The Y-STRs profile obtained is strictly identical to that of Louis XVI (Lucotte et al. , 2016). This establishes that Louis XVI is the biological father of Louis XVII.

Numerous rumours, since the beginning, doubted about Louis XVI paternity of his children. We demonstrate here that Louis-Charles (Louis XVII) is truly Louis XVI's son.

\section{Acknowledgements}

We thank the de Baudreuil brothers who permitted us to study the lock of hair, and Arnaud de Genlis for his complete genealogy of the de Soucy family. This study is included in our research program of genetic investigations developed at the Institute of Molecular Anthropology (Paris) concerning royal families in France.

\section{References}

1. D.W. Deedrick and S.L. Koch (2014). Microscopy of hair, Part 1 : A practical guide and manual for human hairs. Forensic Science Communications, 6 : 1-45.

2. E. Jehaes, H. Pfeiffer, K. Toprak, R. Decorte, B. Brinkmann and J.J. Cassiman (2001). Mitochondrial DNA analysis of the putative heart of Louis XVII, son of Louis XVI and MarieAntoinette. European Journal of Human Genetics, 9 : 185190.

3. G. Lucotte (2010). A rare variant of the mtDNA HVS1 sequence in the hairs of Napoléon's family. Investigative Genetics, 1 (7) : 1-6.

4. G. Lucotte and A. Bouin Wilkinson (2014). An autosomal STR profile of Napoléon the First. Open Journal of Genetics, $4: 292-299$.

5. G. Lucotte, T. Thomasset and C. Crépin (2015). The mitochondrial DNA mitotype of Louis XVII (1785-1795?). International Journal of Sciences, 4 (11) : 10-18.

6. G. Lucotte, T. Thomasset and S. Wen (2016). The DNA YSTRs profile of Louis XVI (1754-1793). International Journal of Sciences, 5 (04) : 68-93. 
Figure 1 : A : The ring of Marie-Antoinette. B : The ring into its case. C : The folded letter.

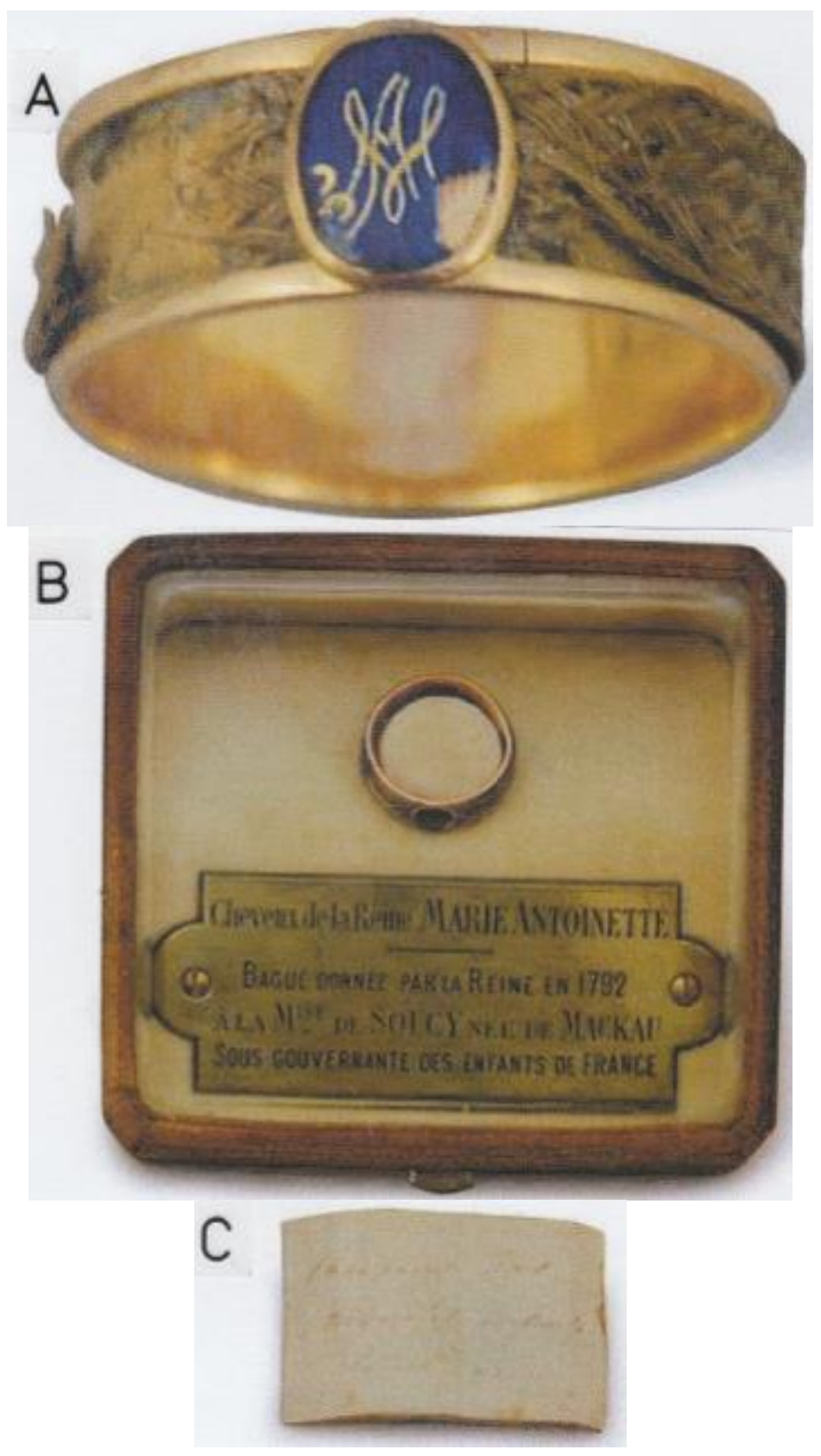


Figure 2 : Above : The folded letter, with inscriptions. Below : The letter, unfolded, containing hairs and the green thread.

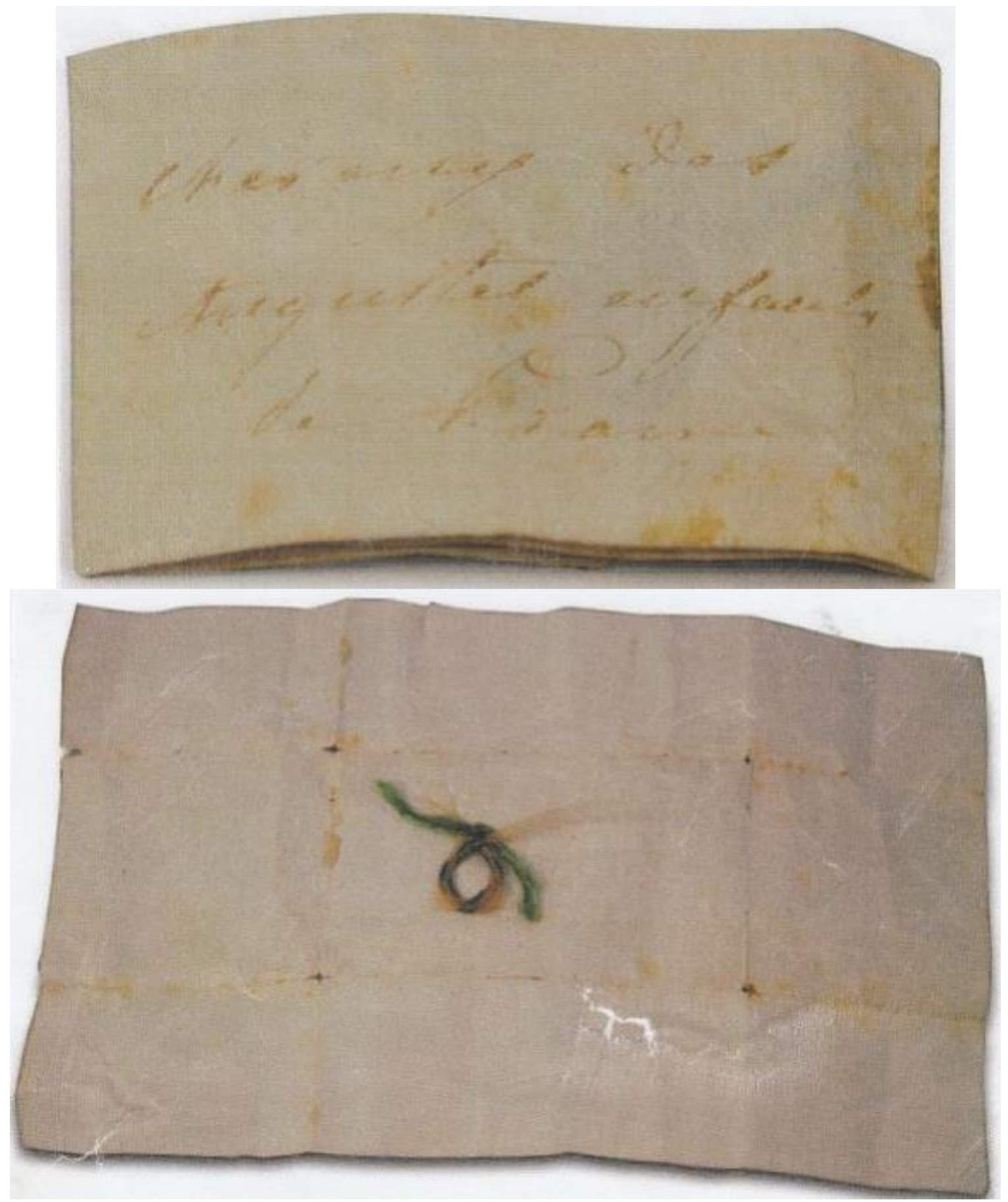


Figure 3 : Above photograph : Optical view (5x) of the paper corner. Below photograph : SEM-1 photograph (in GSE, 100x) of the paper. Below : Global spectrum of the paper. C : carbon ; O : oxygen ; $\mathrm{Mg}$ : magnesium ; Al : aluminium ; $\mathrm{S}$ : sulphur ; $\mathrm{K}$ : potassium ; $\mathrm{Ca}$ (two peaks) : calcium.




Figure 4 : Fibers of the paper. Above : SEM-1 photograph (in GSE, 1200x) showing a paper fiber (N : nodes) ; the black dot on it indicates the location where elemental analysis is realized. Below : Spectrum at the black dot.

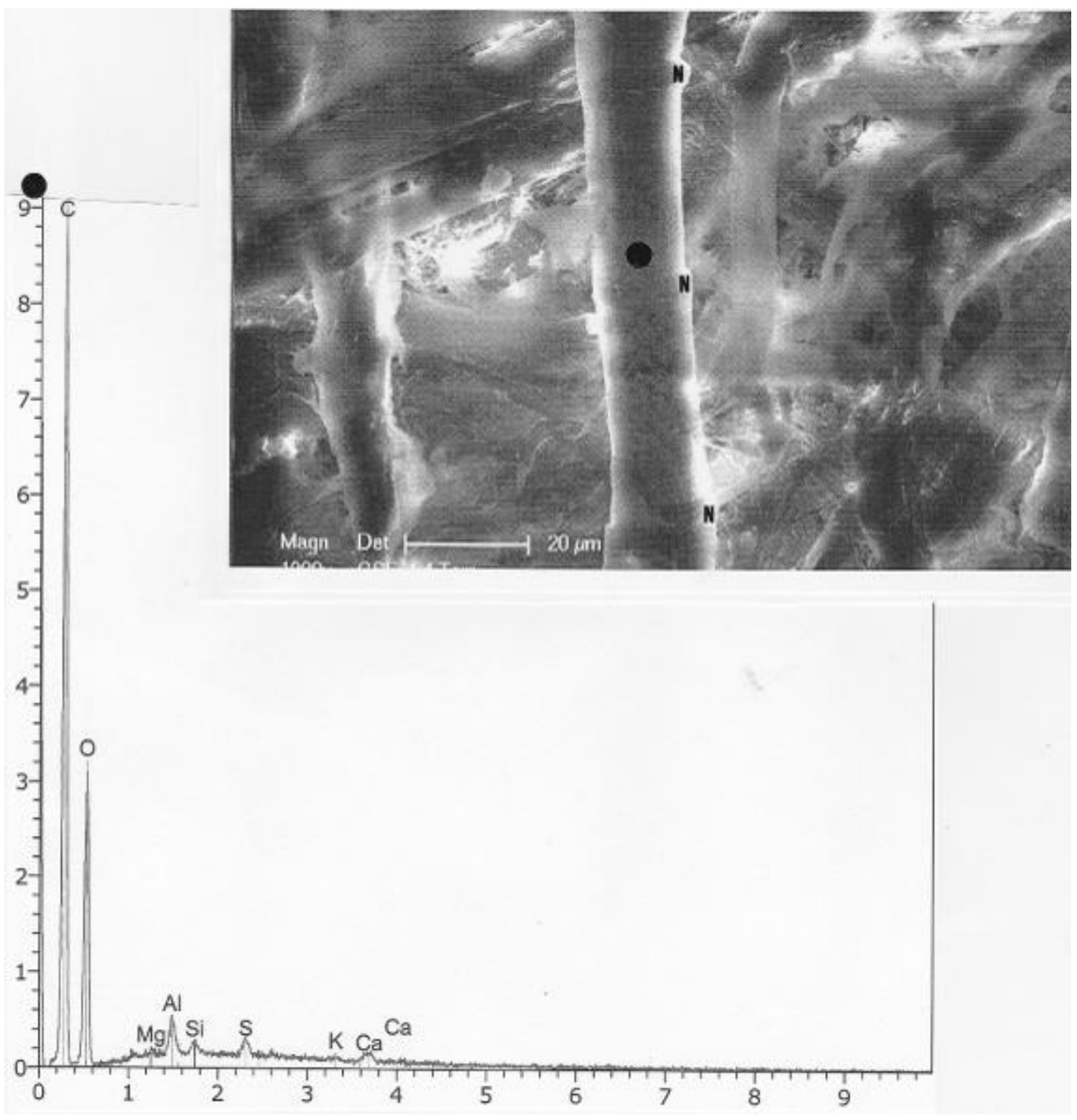


Figure 5 : The ink. Above : Optical view (50x) of the s' point (M : plastic marker). Below : SEM-1 photograph (in GSE, 100x) of the same paper region.

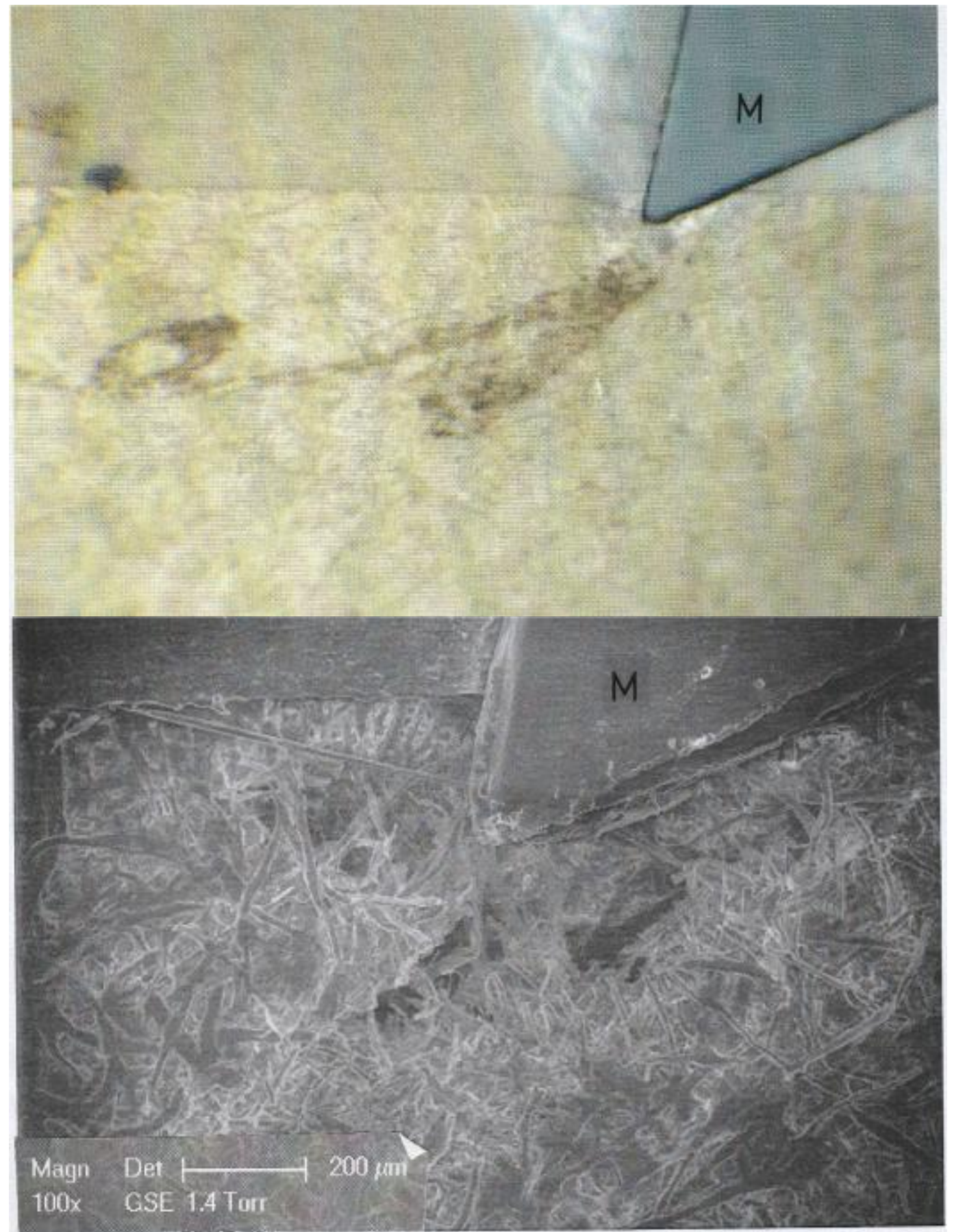


Figure 6 : Above : SEM-1 photograph (in BSE, 400x) centred on the same region. Below : Spectrum at the black dot. $\mathrm{Fe}$ (three peaks) : iron ; Na : sodium ; $\mathrm{Si}$ : silicium.

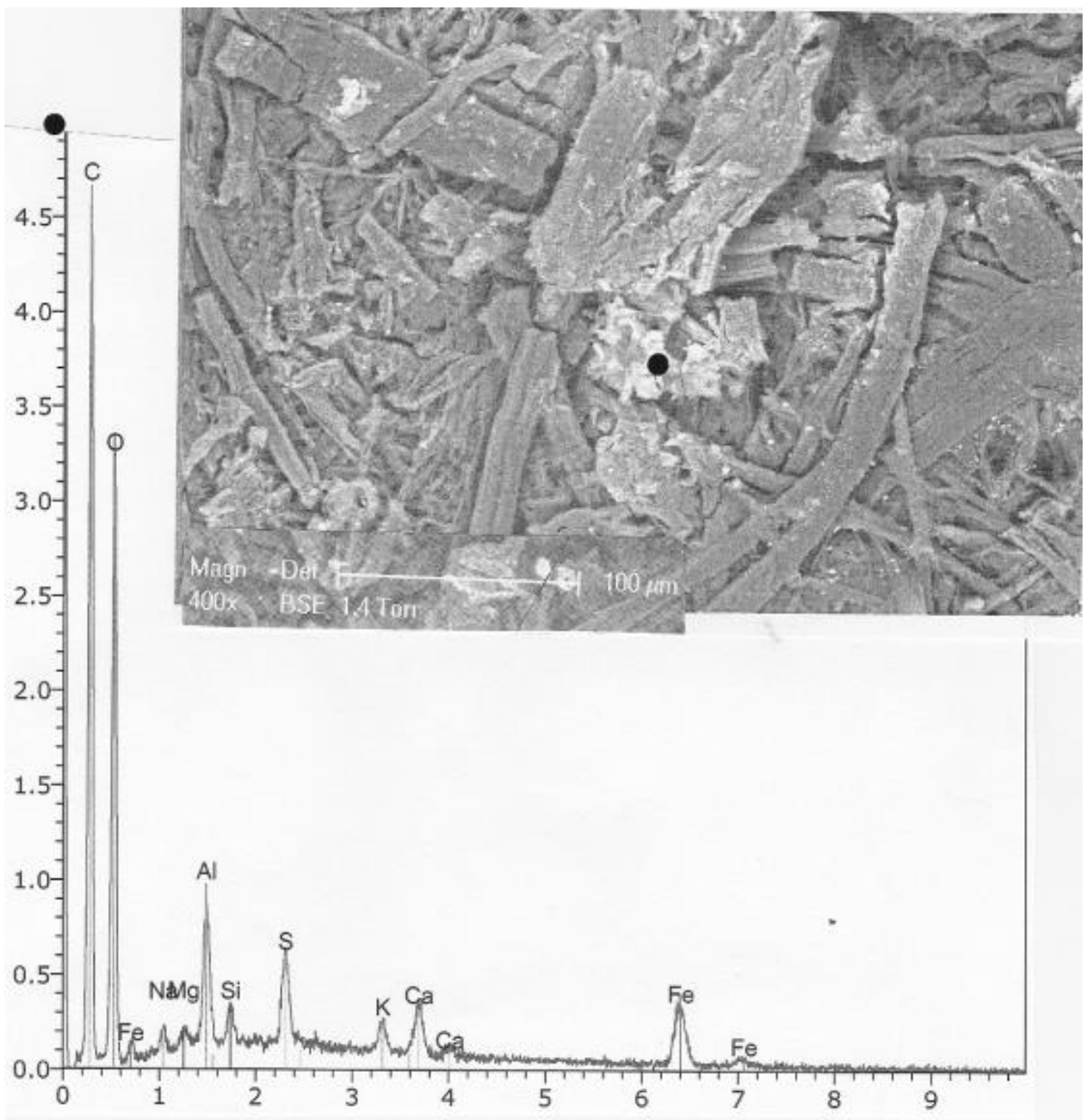


Figure 7 : The lock of hairs. Optical view $(75 x)$ of the lock. $G$ : the various portions of the green thread $(\mathrm{N}:$ the thread node) ; $\mathrm{RH}$ : red hairs ; $\mathrm{BH}$ : blond hair.

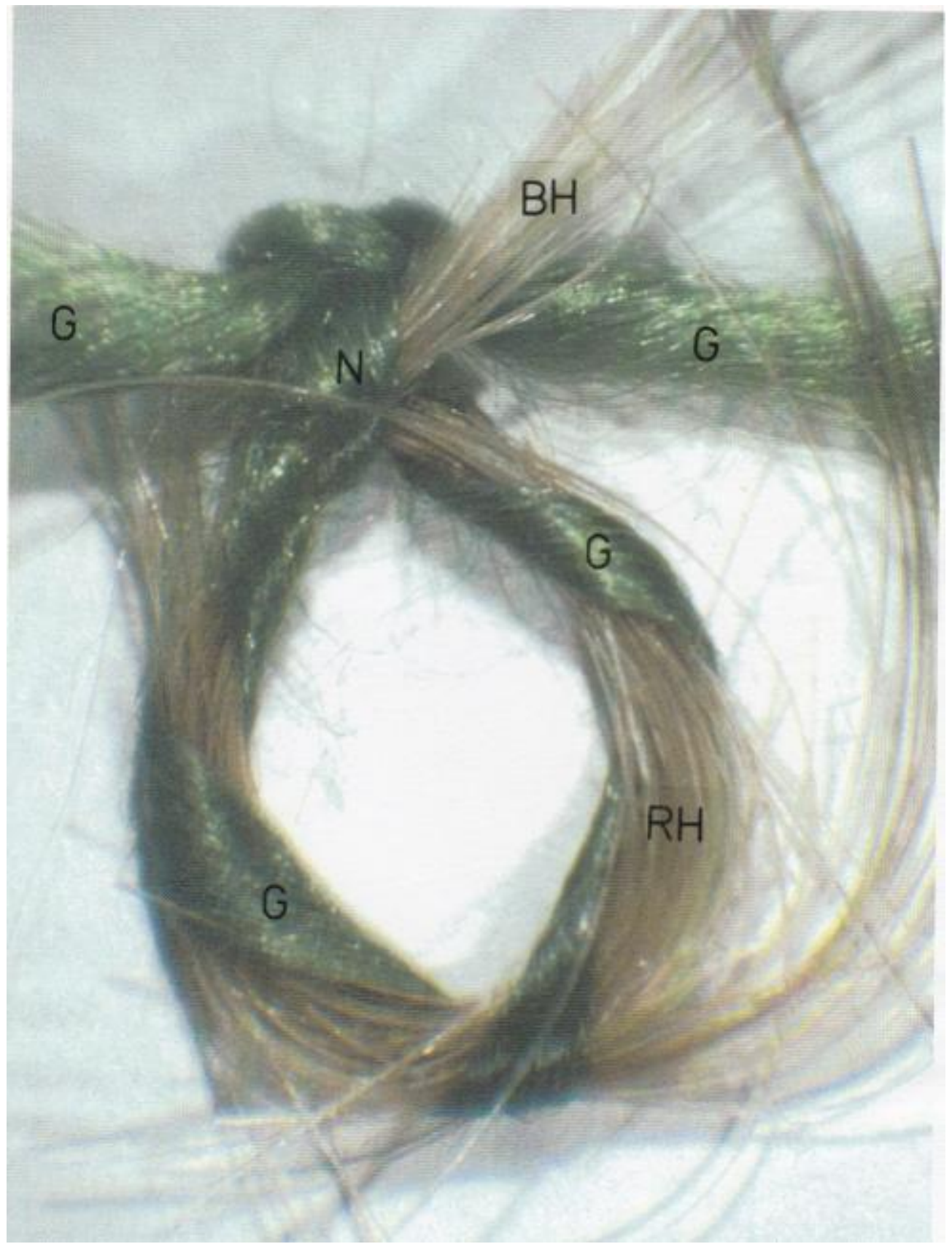


Figure 8 : The green thread. A : Optical view (110x) of the thread fibers. B : SEM-1 photograph (in GSE, 100x) of the fibers. C : SEM-1 photograph (in GSE, 6000x) of a fiber extremity.

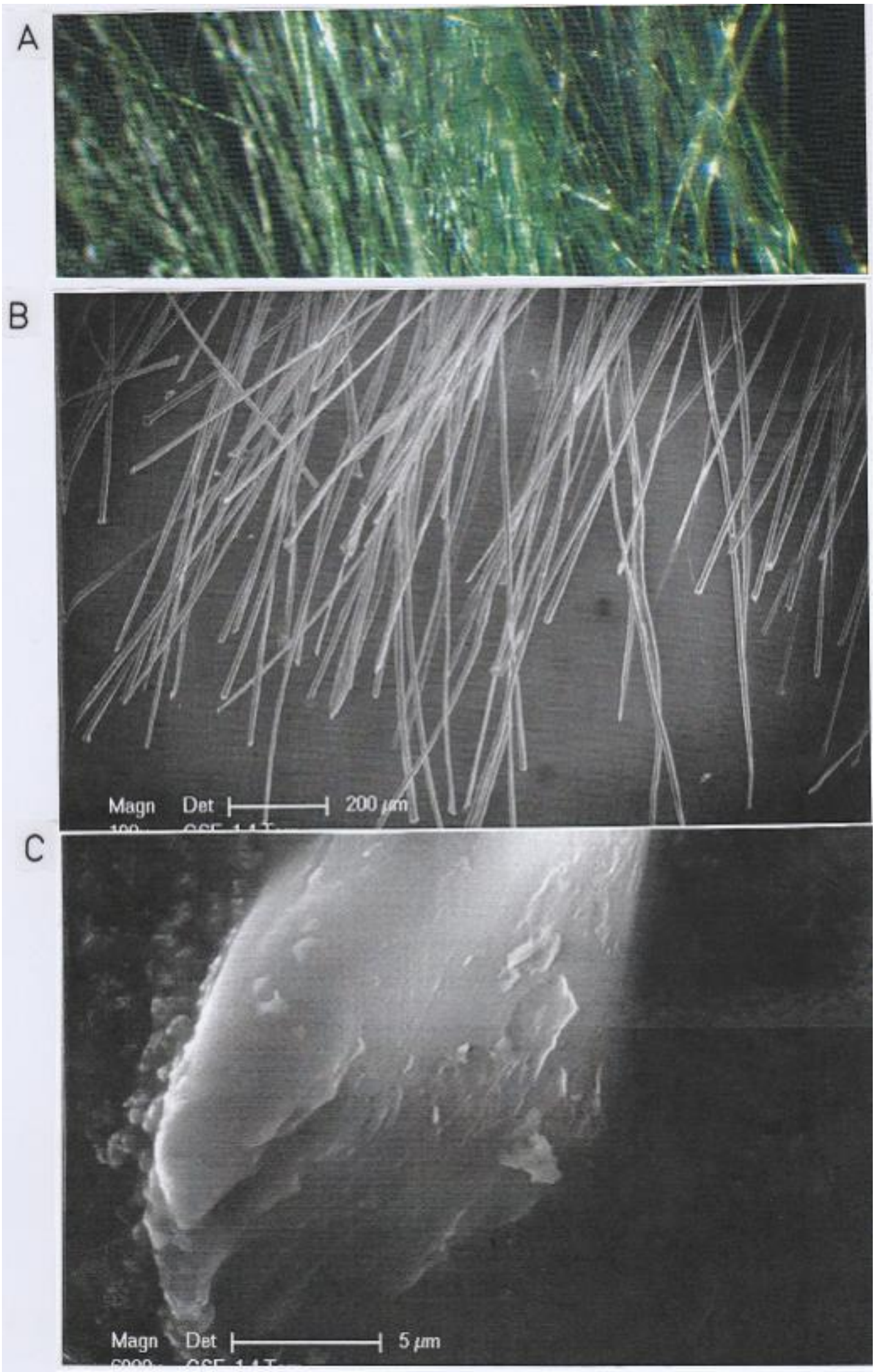


Figure 9: Three fiber portions. Above : SEM-1 photograph (in GSE, 3000x) of the fiber portions (dimension is in $\mu \mathrm{m})$. Below: Spectrum at the black dot (N : nitrogen).

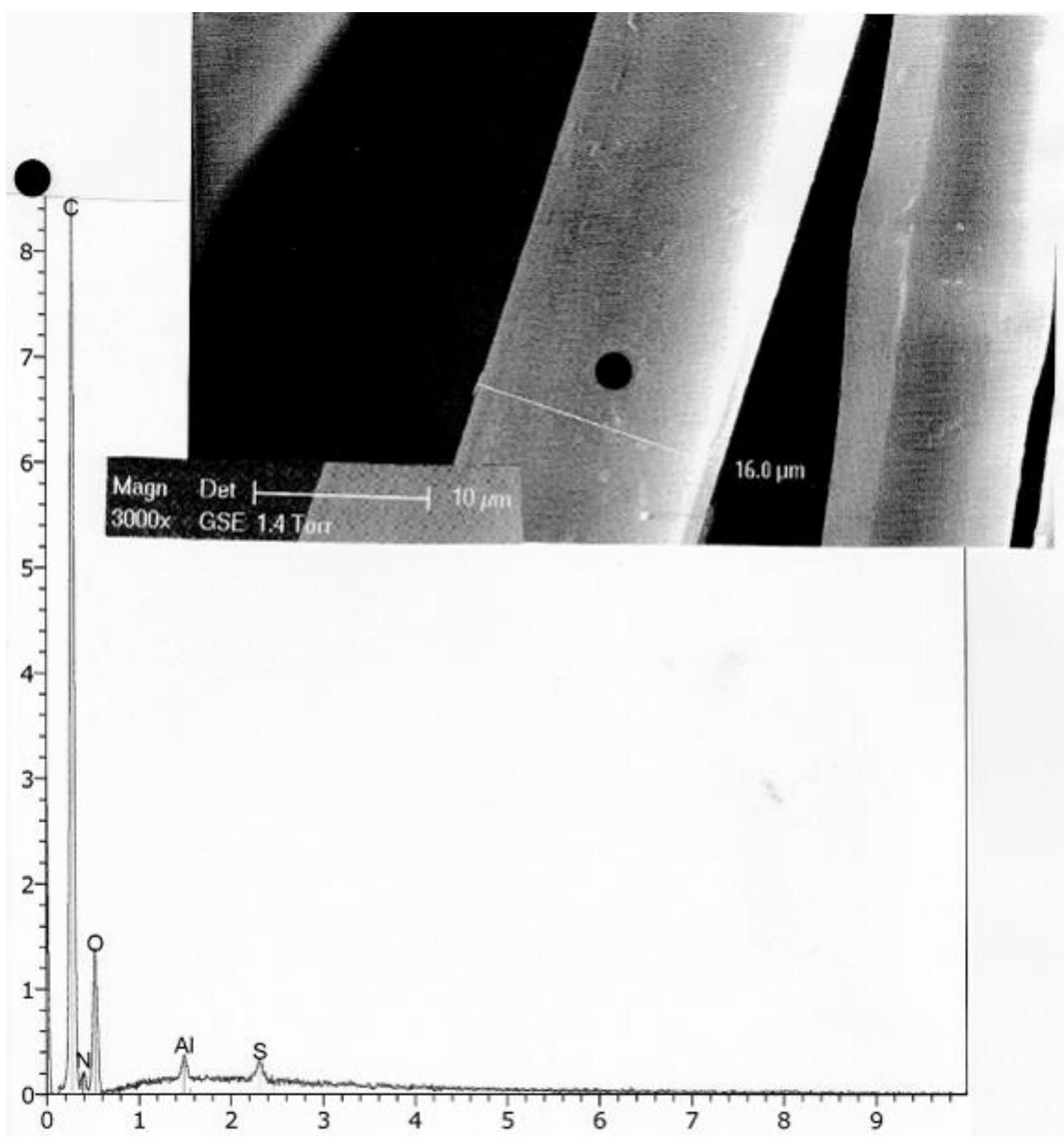


Figure 10 : The studied hairs. Above : Optical view of three (1-3) red hairs. Below : Optical view of three (1-3) blond hairs ( the second one being tripartite).

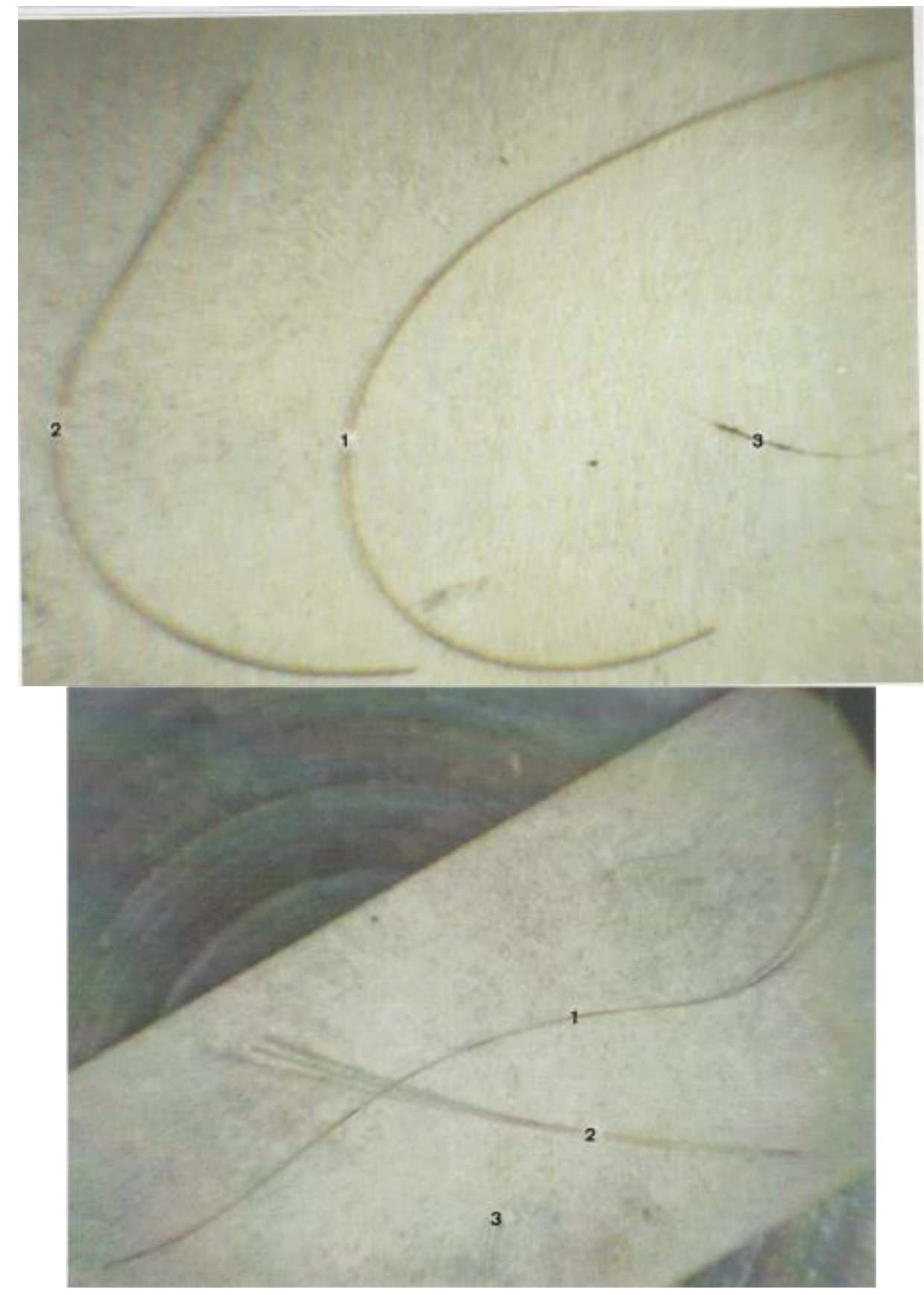


Figure 11 : SEM-1 photograph (in GSE) of the right (1500x) end (above) and of the left (1000x) end (below) of the red hair number 1 .

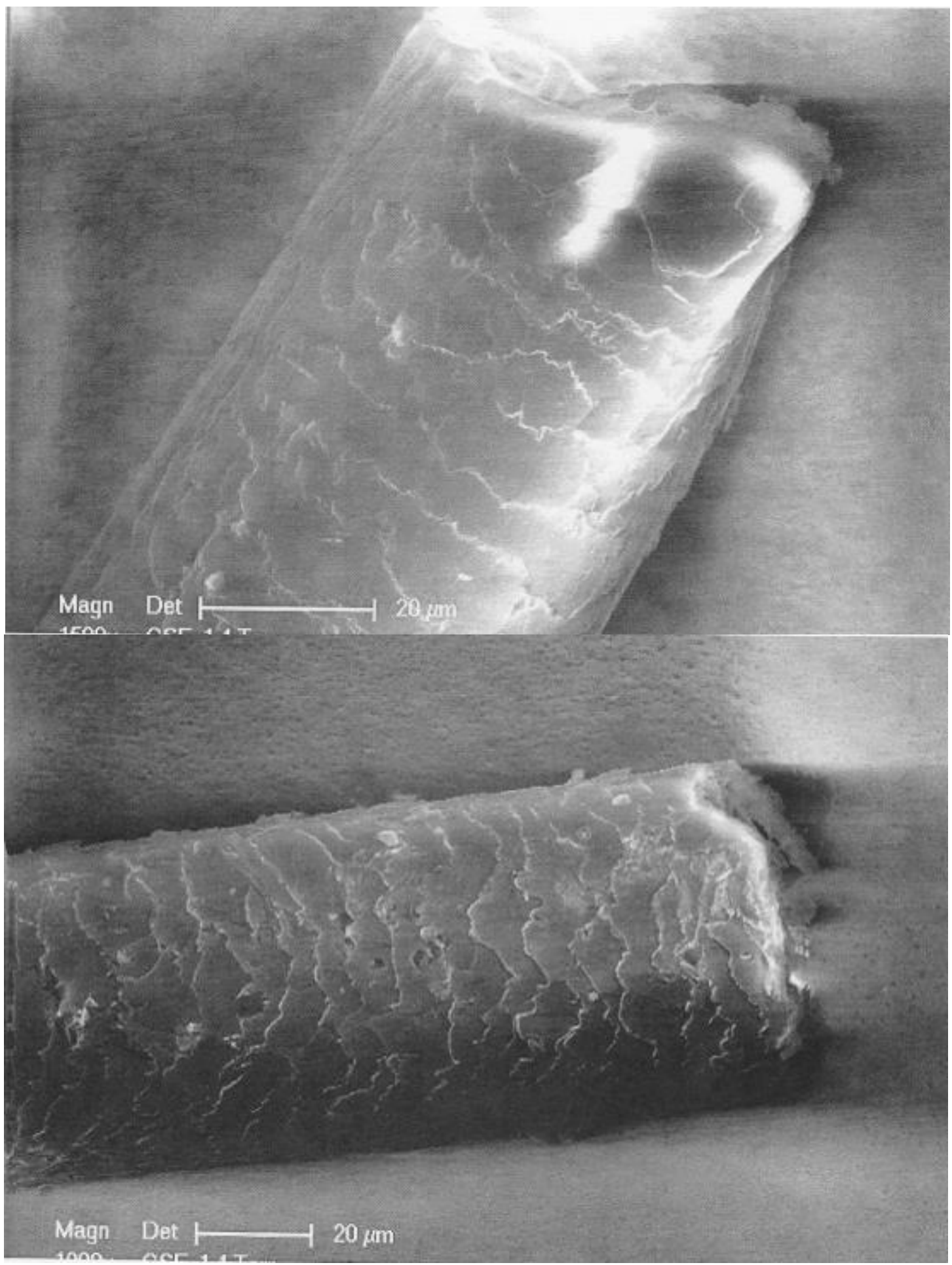


Figure 12 : Above : SEM-1 photograph (in GSE, 1200x) of a portion of the hair corresponding to its middle part (dimension in $\mu \mathrm{m}$ ). Below : Spectrum at the black dot. C : carbon ; N : nitrogen ; O : oxygen ; Na : sodium ; S (two peaks) : sulphur ; $\mathrm{Cl}$ : chlorine ; $\mathrm{K}$ : potassium ; $\mathrm{Ca}$ (two peaks) : calcium.

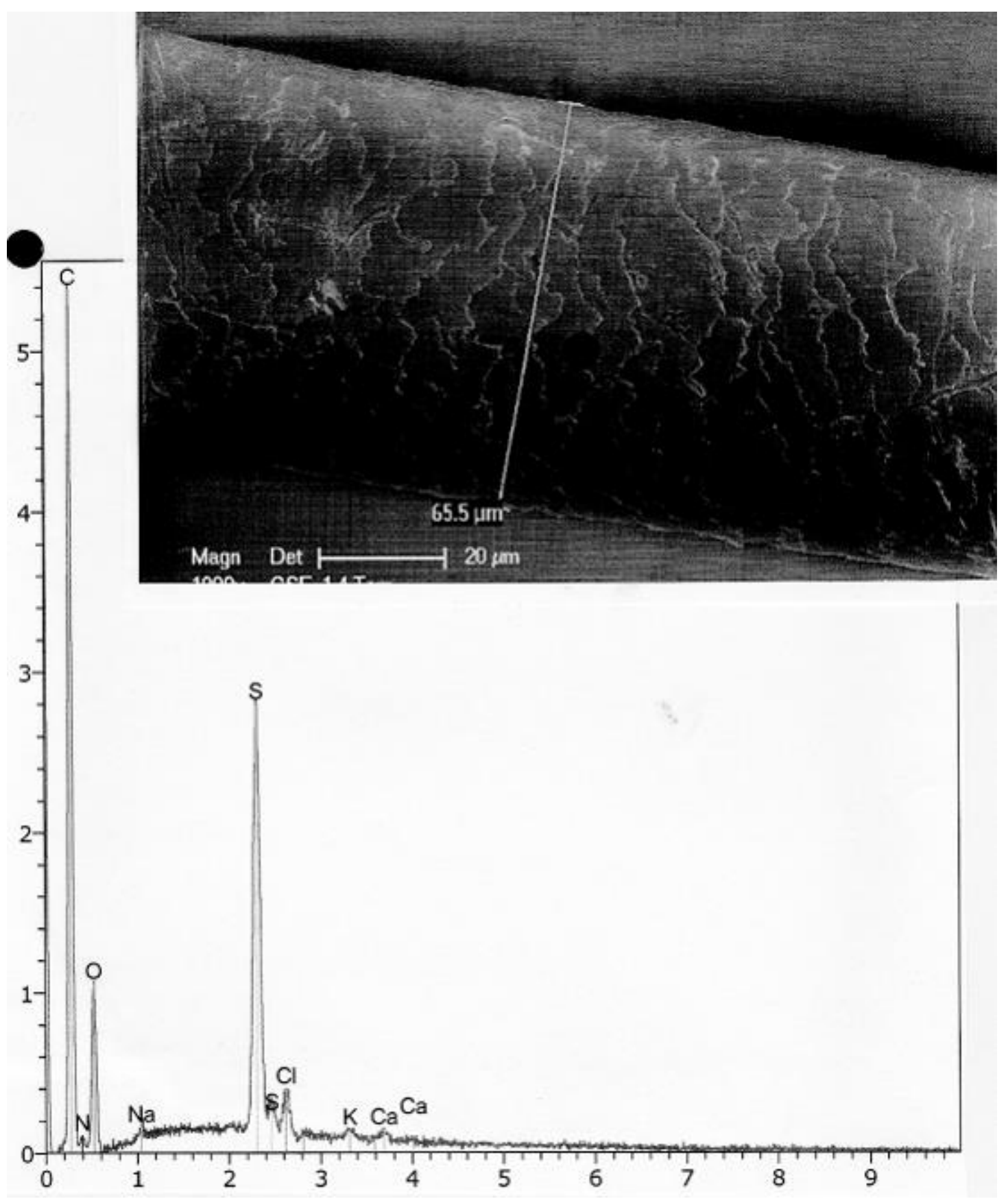


Figure 13 : Above : SEM-1 photograph (in GSE, 3000x) of the hair portion showing a mineral particle. Below : Spectrum of the particle. $\mathrm{C}$ : carbon ; $\mathrm{N}$ : nitrogen ; $\mathrm{O}$ : oxygen ; $\mathrm{Fe}$ (three peaks) : iron ; $\mathrm{Mg}:$ magnesium ; $\mathrm{Al}$ : aluminium ; $\mathrm{Si}$ : silicium ; $\mathrm{S}$ (two peaks) : sulphur ; $\mathrm{Cl}$ : chlorine ; $\mathrm{K}$ : potassium ; $\mathrm{Ca}$ (two peaks) : calcium.

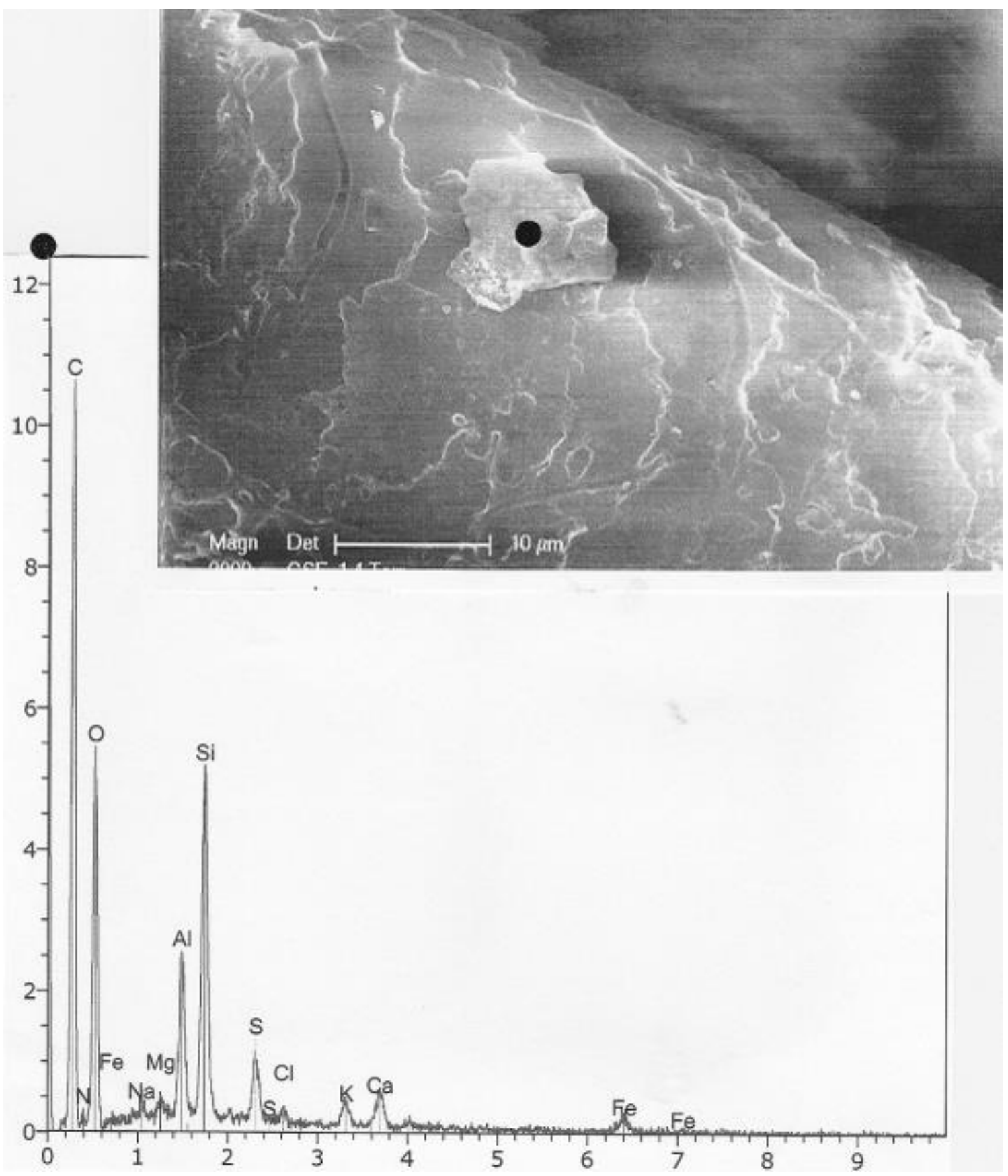


Figure 14 : Above : SEM-1 photograph (in GSE, 1500x) of another hair portion showing another sort of mineral particle. Below : Spectrum of the particle. C : carbon ; O : oxygen ; Na : sodium ; S (two peaks) : sulphur ; $\mathrm{Cl}$ : chlorine ; $\mathrm{Ca}$ (two peaks) : calcium.

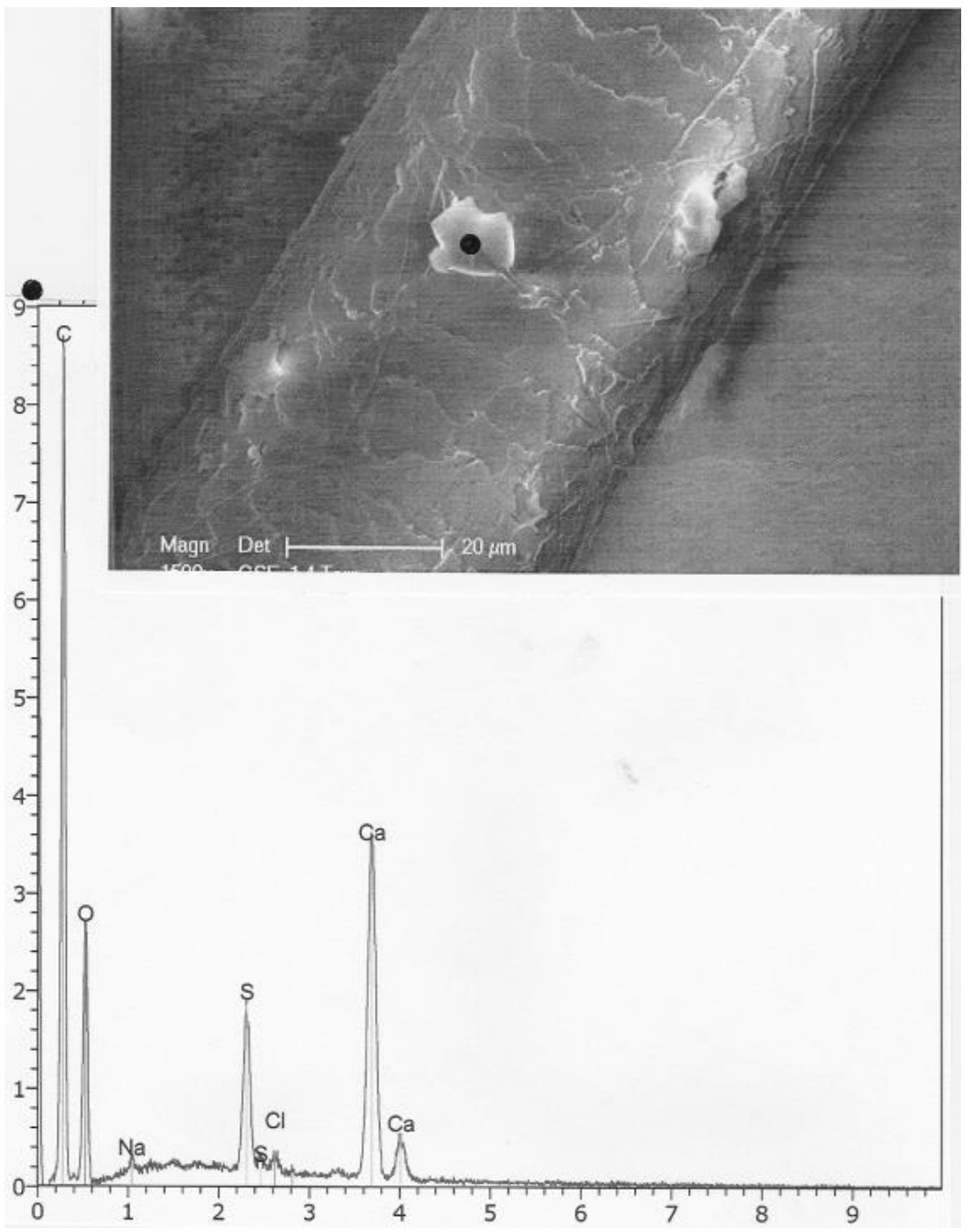


Figure 15 : Above : SEM-1 photograph (in BSE, 2000x) of an Acari. Below : SEM-1 photograph (in BSE, 2000x) of an insect clutch.

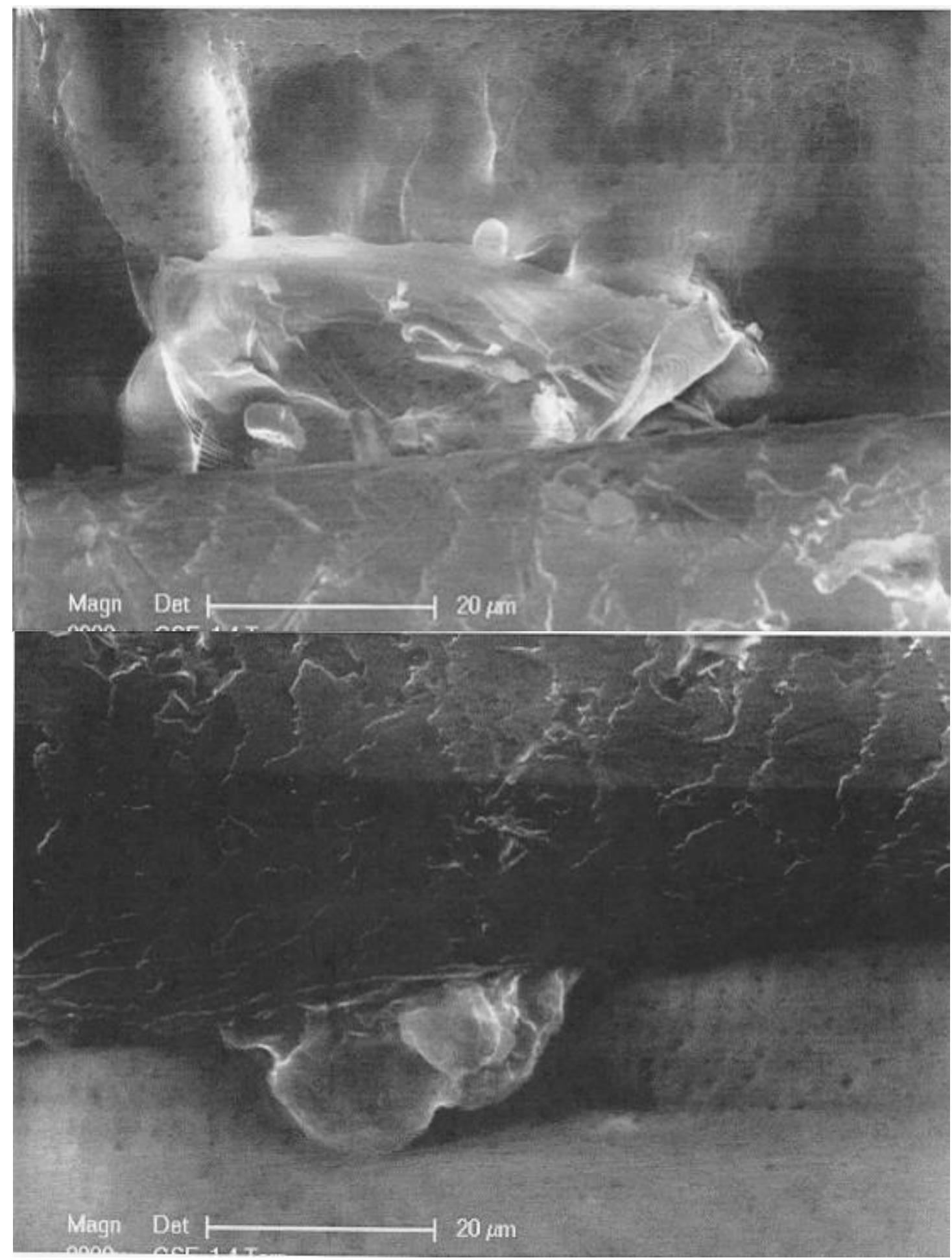


Figure 16: Above : SEM-1 photograph (in GSE, 1500x) of an hair portion showing a rounded particle deposited on it. Below : Spectrum of the particle. C : carbon; O : oxygen ; Fe (three peaks) : iron ; Na : sodium ; S (two peaks) : sulphur.

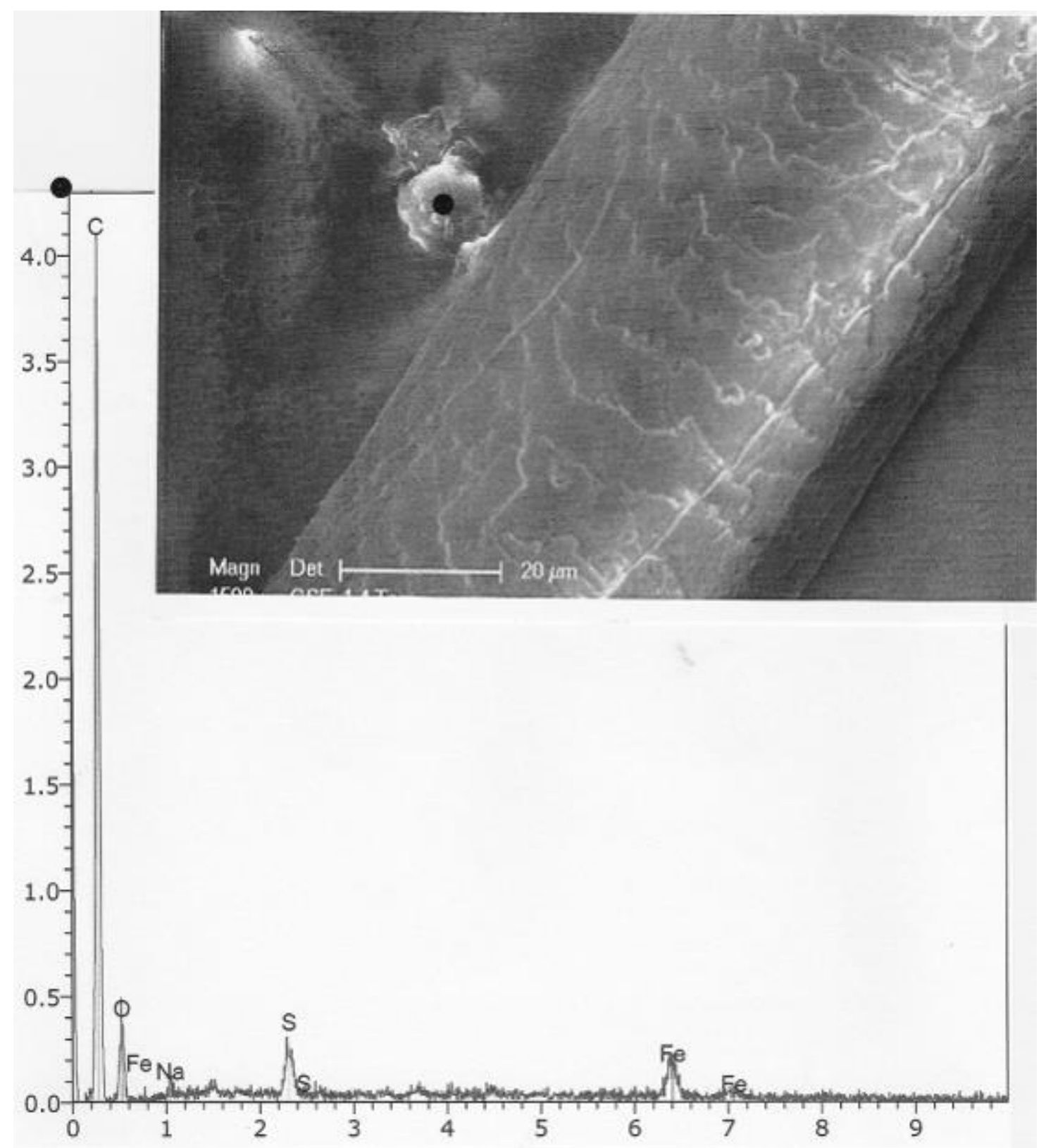


Figure 17. Above : SEM-1 photograph (in GSE, 1500x) of coiled filaments of a Cyanophycae, loaded on the hair surface. Below : Muti-elements spectrum of the Cyanophycae.

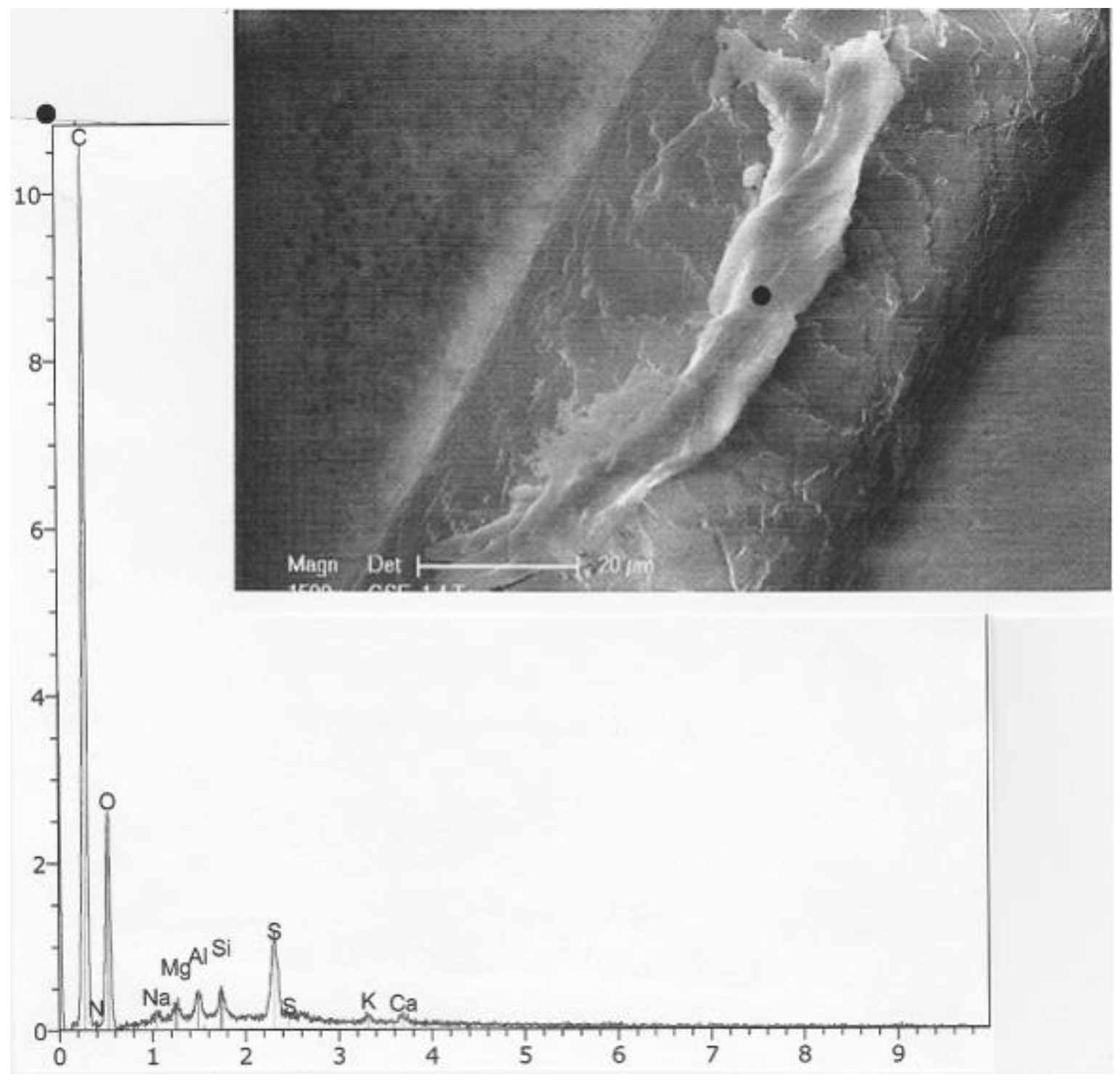


Figure 18 : SEM-1 photograph (in GSE) of the right (1200x) end (above) and of the left (1000x) end (below) of the blond hair number 1 .
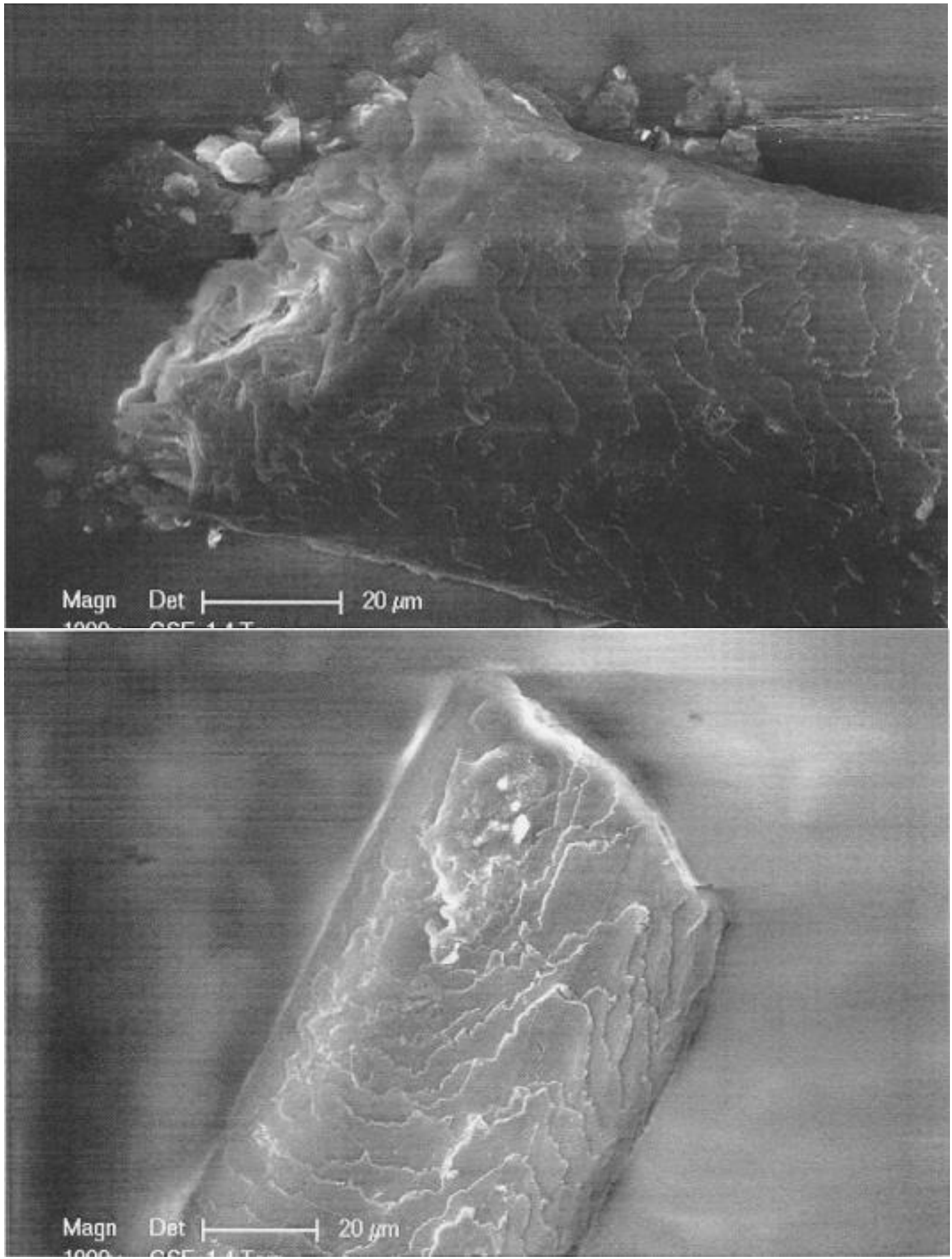
Figure 19 : Above : SEM-1 photograph (in GSE, 1500x) of a portion of the hair corresponding to its middle part (dimension in $\mu \mathrm{m})$. Below: Spectrum at the black dot.

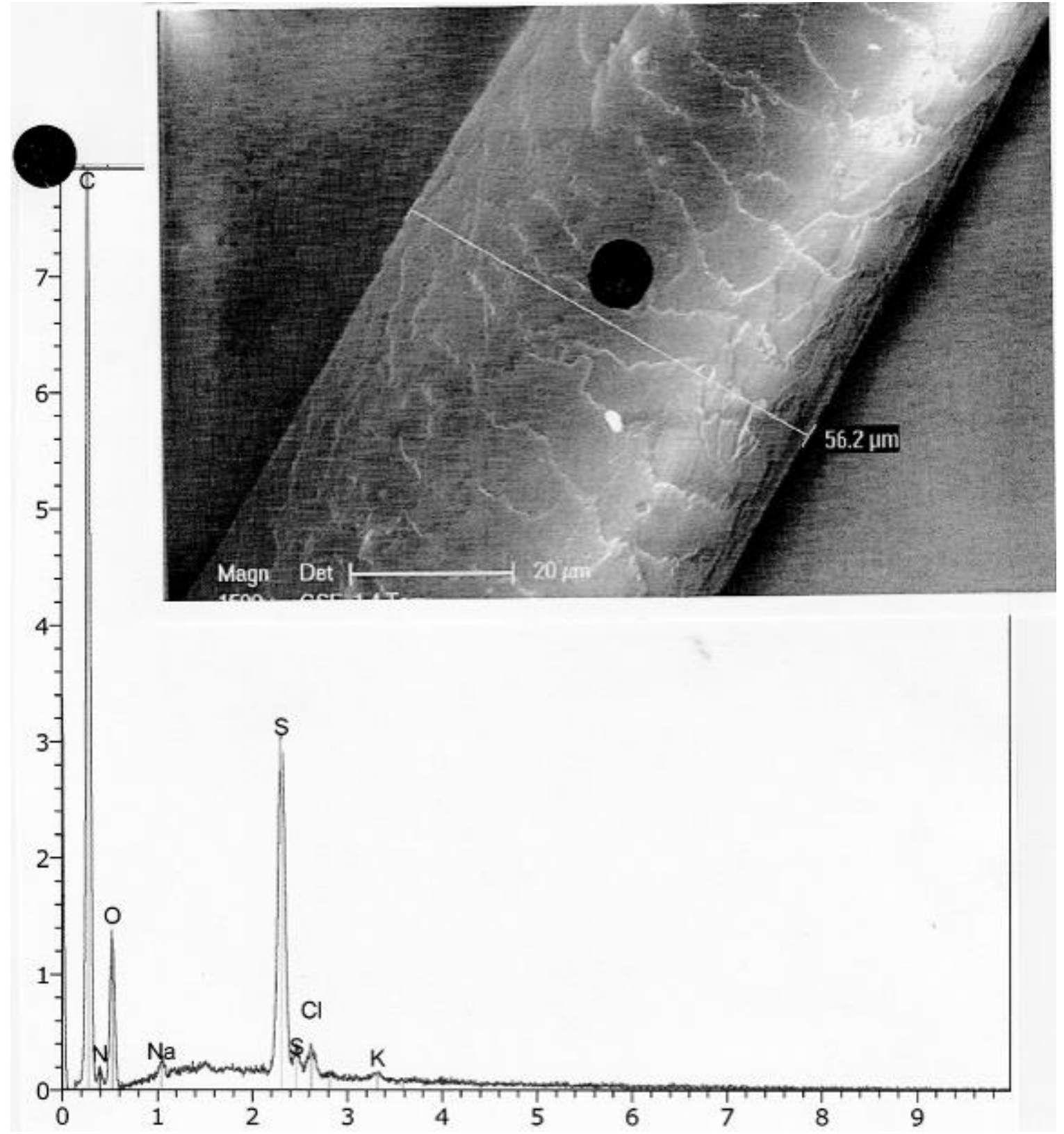


Figure 20 : Above : SEM-1 photograph (in GSE, 2000x) of a skin-cell, adhering to the hair surface. Below : Spectrum at the black dot. $\mathrm{C}$ : carbon ; $\mathrm{N}$ : nitrogen ; $\mathrm{O}$ : oxygen ; Na : sodium ; P : phosphorous ; $\mathrm{S}$ (two peaks) : sulphur ; $\mathrm{Cl}$ : chlorine ; $\mathrm{K}$ : potassium ; $\mathrm{Ca}$ (two peaks) : calcium.

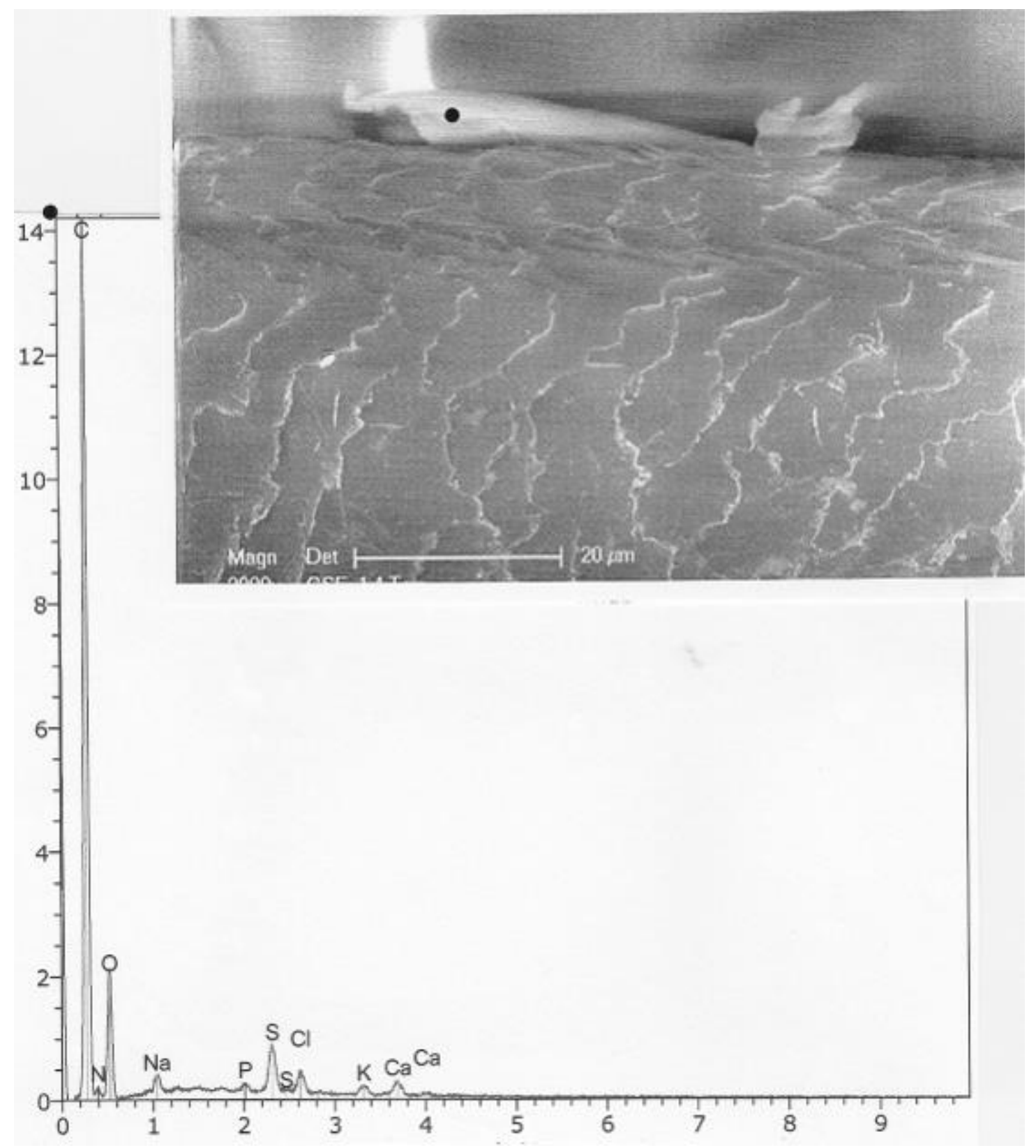


Figure 21 : Above : SEM-1 photograph (in GSE, 1500x) of a micel located on the hair surface. Below : Spectrum at the black dot.

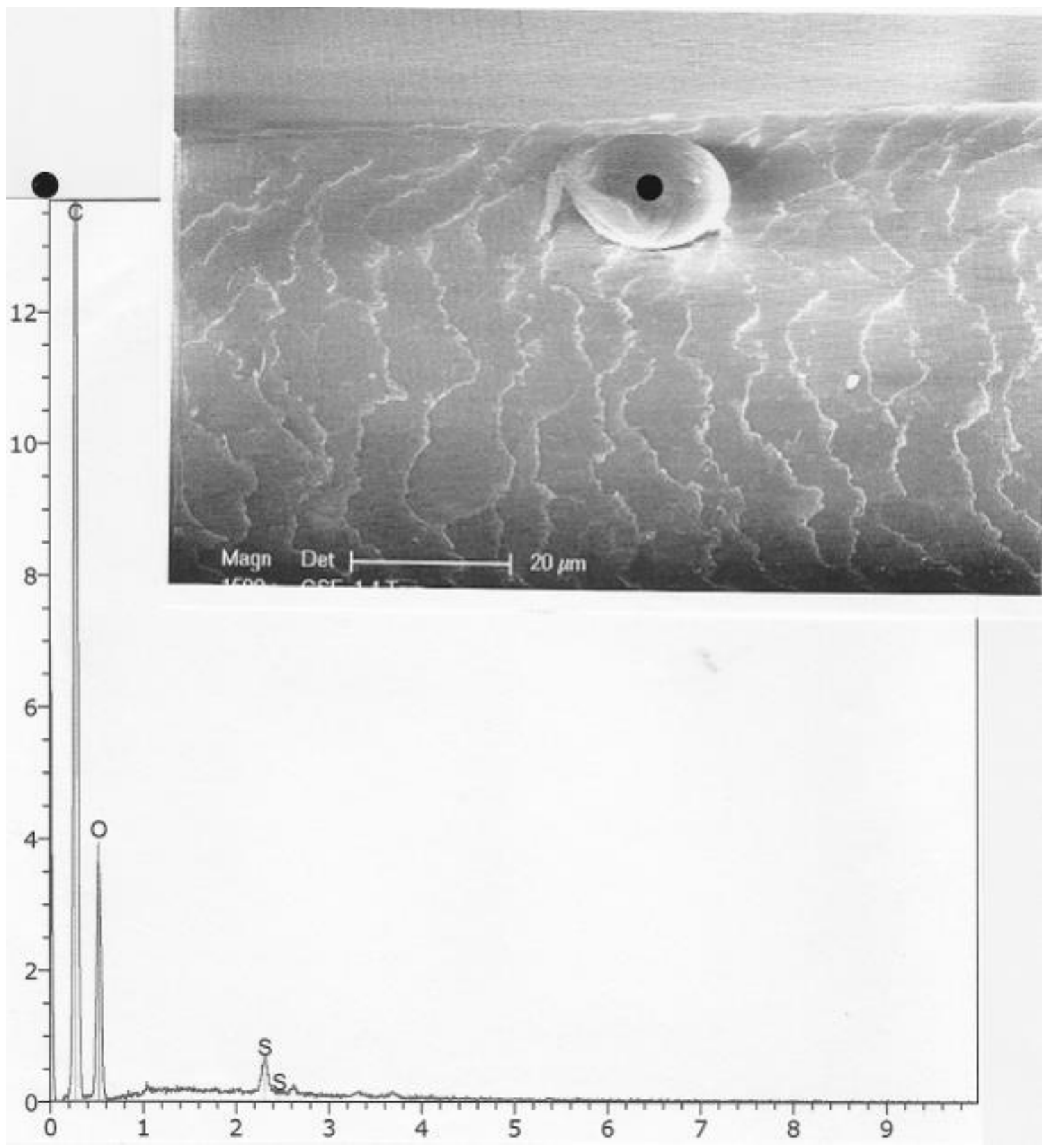


Figure 22 : Above : SEM-1 photograph (in GSE, 4000x) showing metallic particles located on the hair surface. Below : Spectrum at the black dot. $\mathrm{C}$ : carbon ; N : nitrogen ; O : oxygen ; Cu (three peaks) : copper ; $\mathrm{S}$ (two peaks) : sulphur ; $\mathrm{Cl}$ : chlorine ; $\mathrm{Ag}$ (three peaks) : copper ; $\mathrm{S}$ (two peaks) : sulphur ; $\mathrm{Cl}$ : chlorine ; $\mathrm{Ag}$ (three peaks) : silver ; $\mathrm{Ca}$ (two peaks) : calcium.

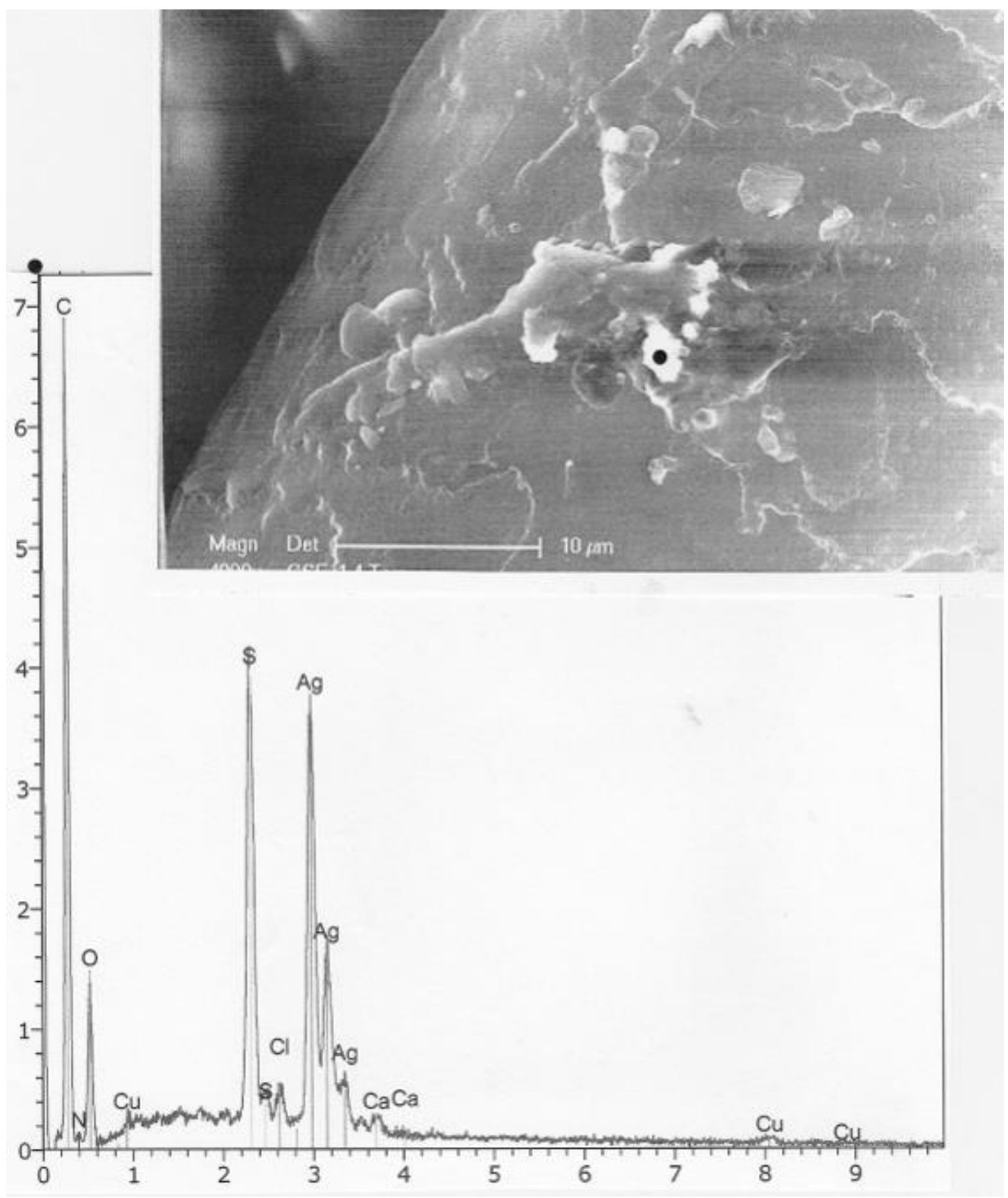


Figure 23 : Above : SEM-1 photograph (in GSE, 2000x) of a set of particles located on the hair surface. Below : Spectrum at the black dot.

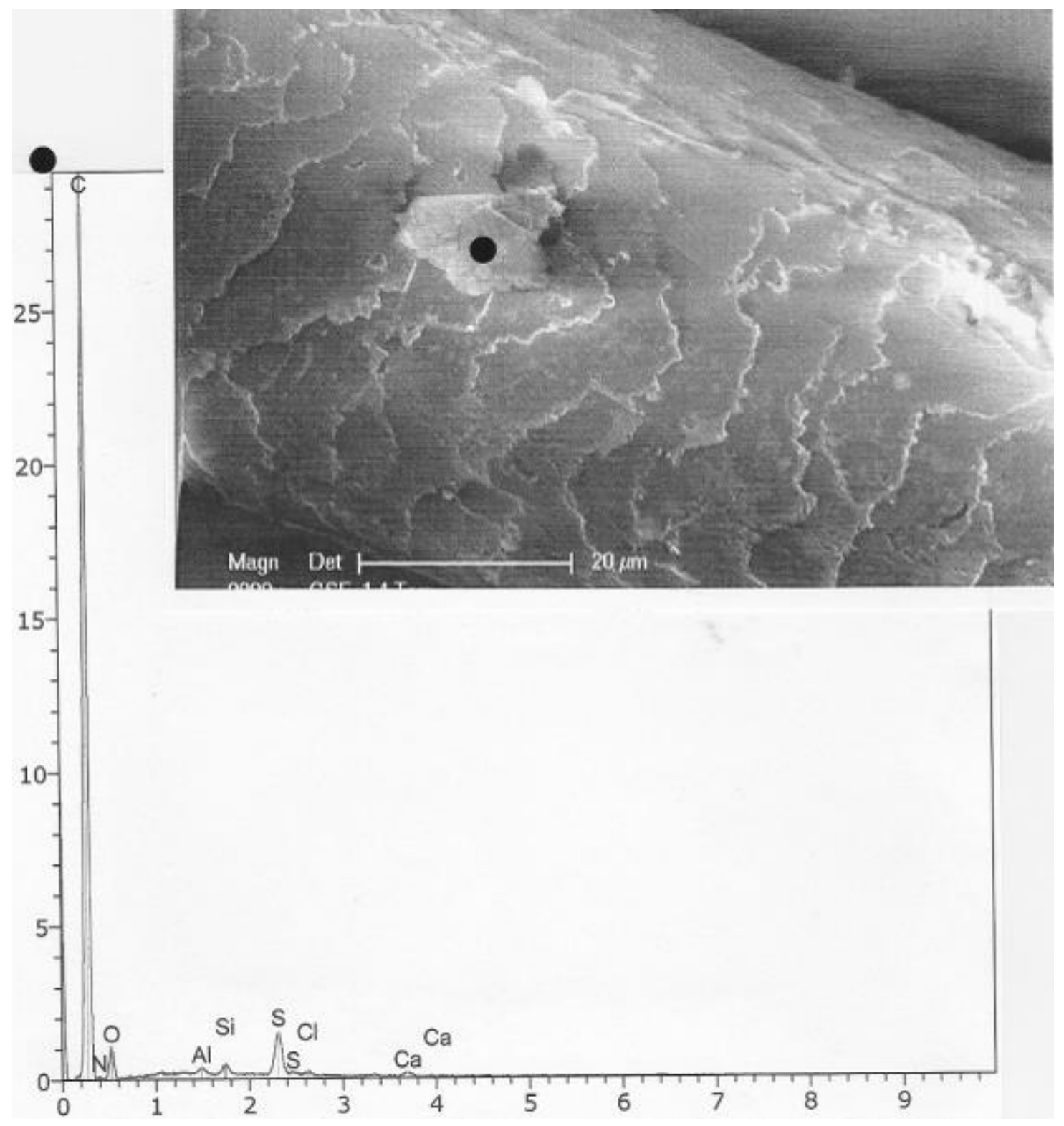


Figure 24 : Above : SEM-2 photgraph (in LFD, 2400x) of a skin-cells (F : folds). Below : Spectrum at.+

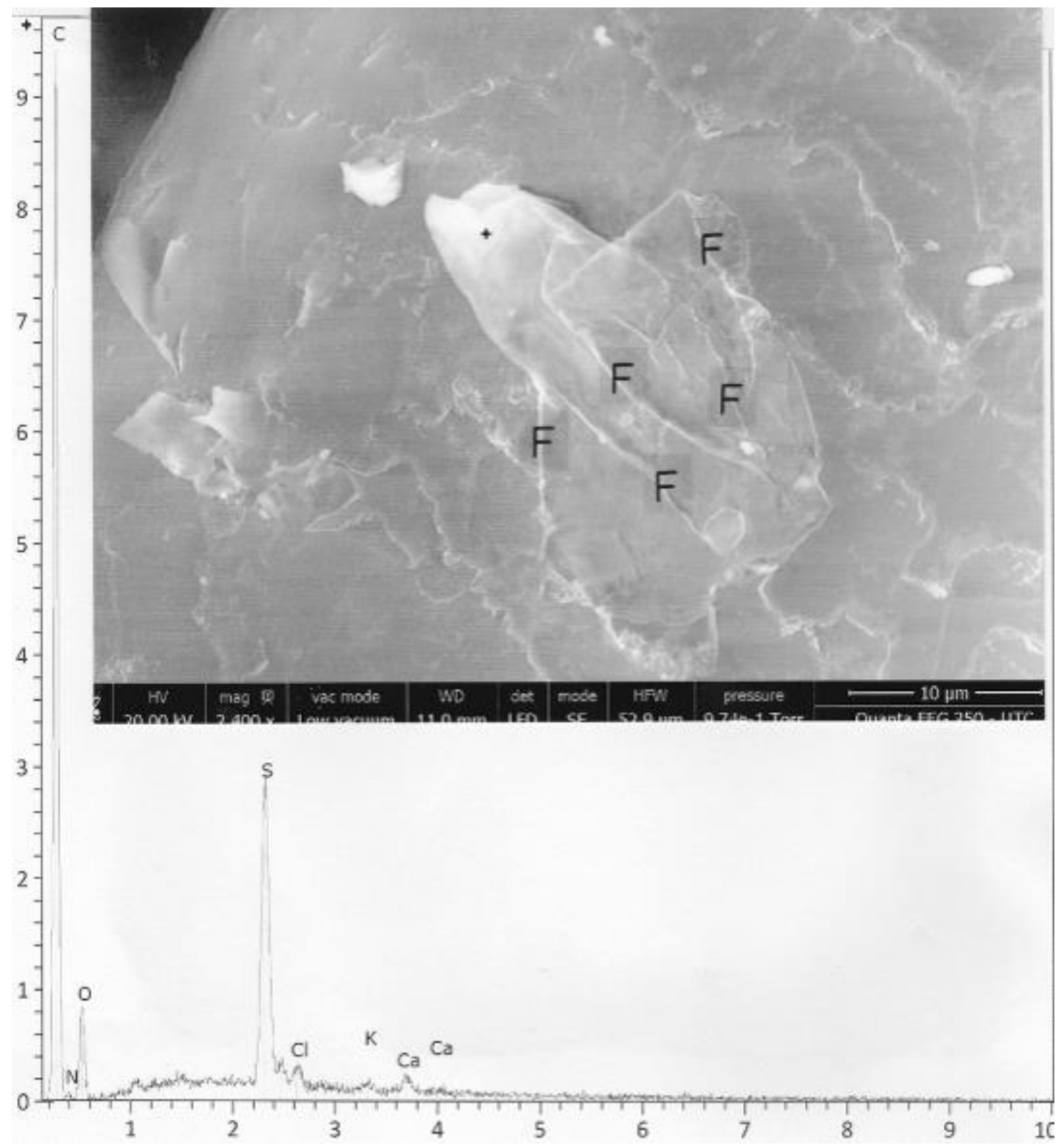


Figure 25 : Above : SEM-2 photograph (in LFD, 2400x) of the first (1) dandruff observed. Below : Spectrum at 1.

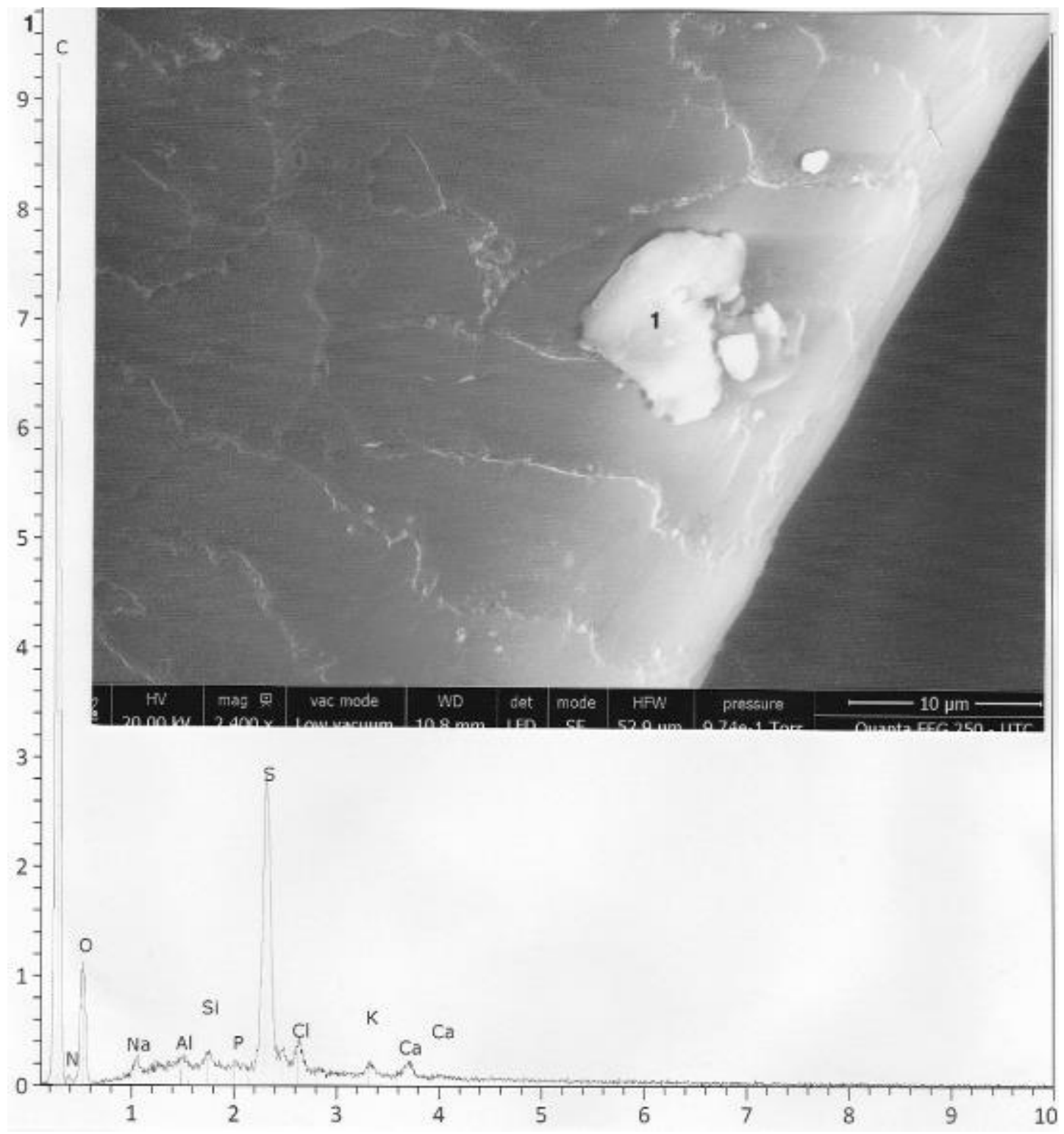


Figure 26: Above : SEM-2 photograph (in LFD, 2400x) of the second (2) dandruff observed. Below : Spectrum at 2.

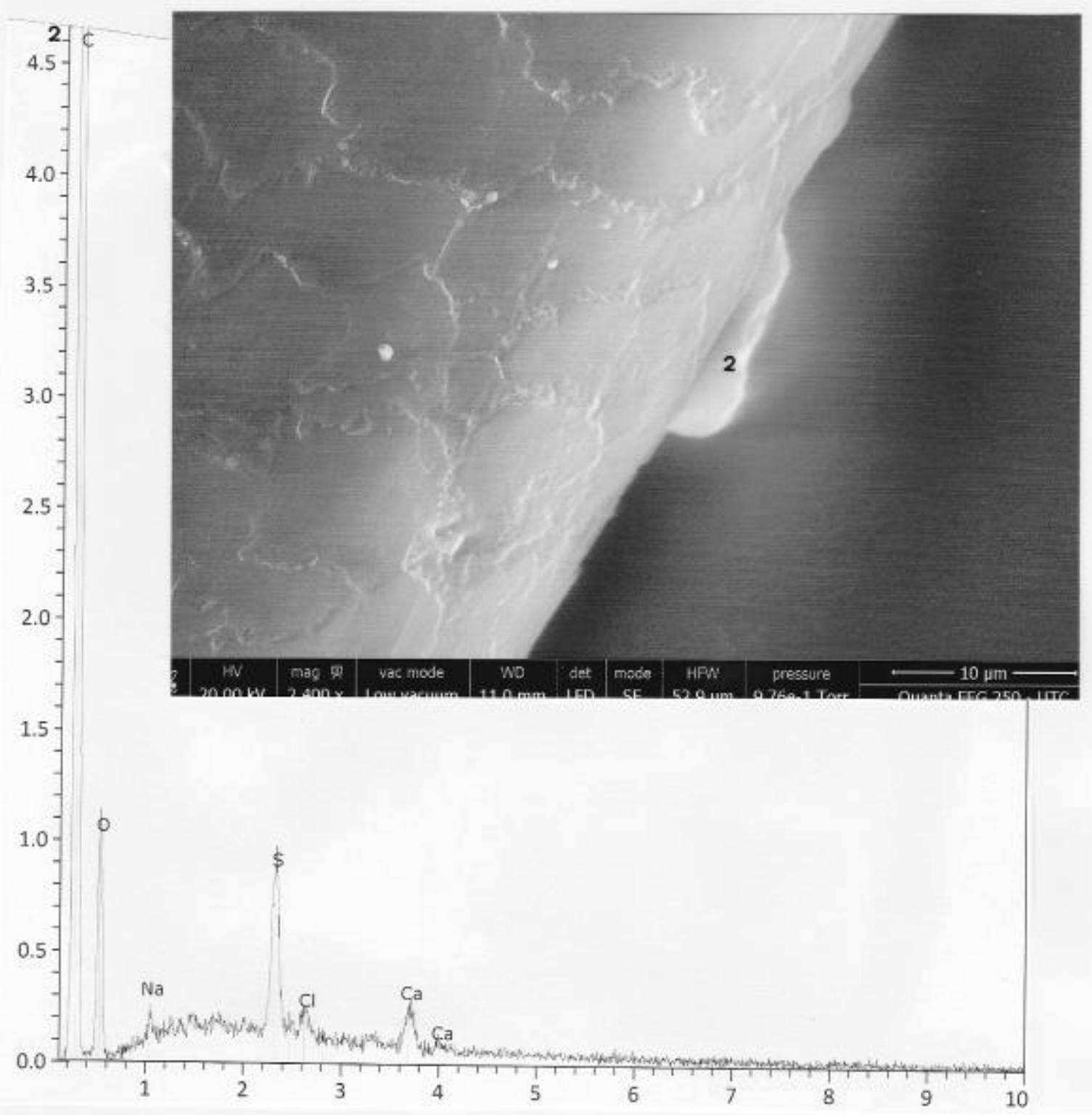


Figure 27 : SEM-2 photographs (in LFD, 2400x) of the third (3) and fourth (4) dandruffs observed.

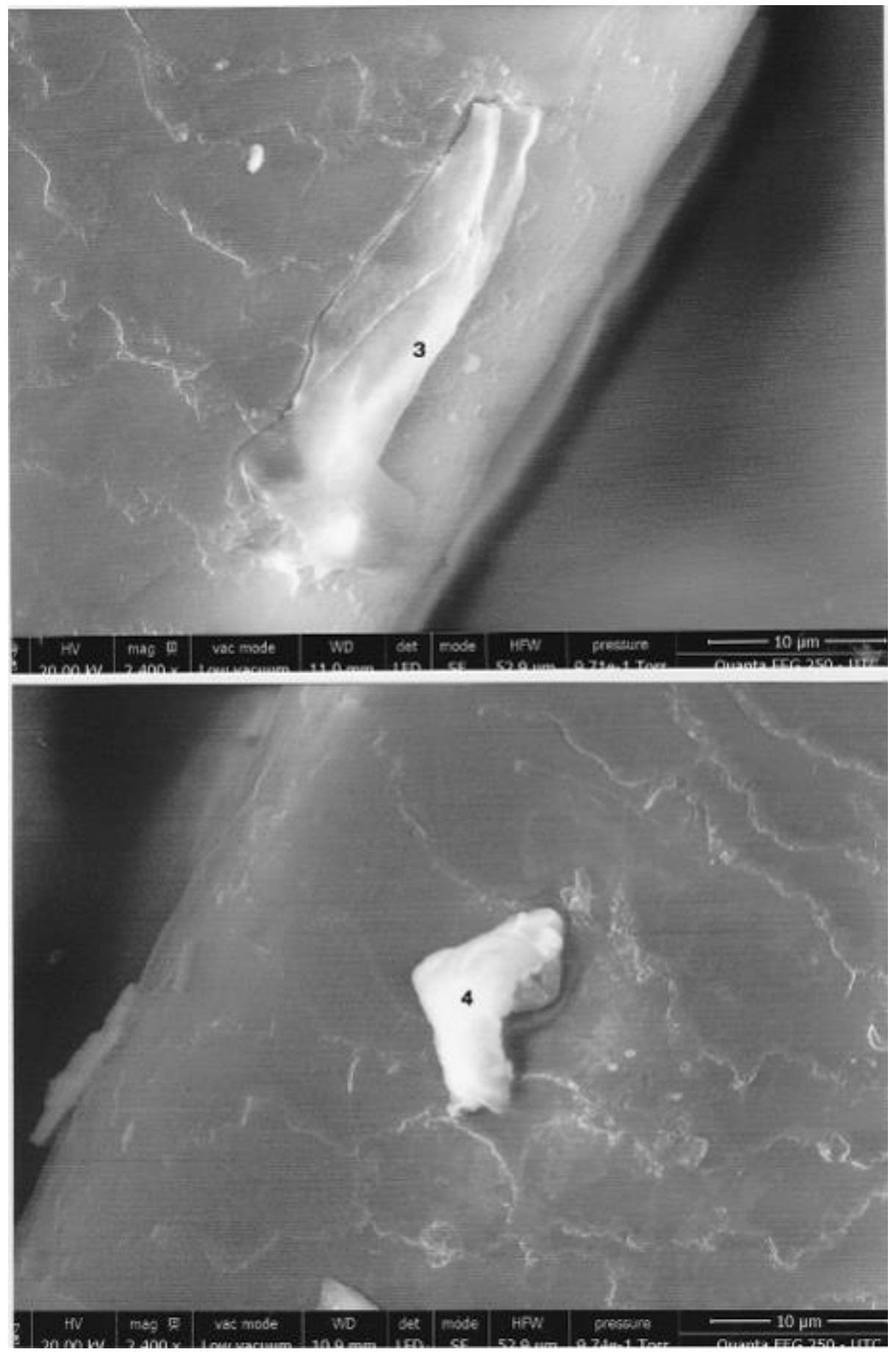

